\title{
A Space That Will Never Be Filled Sharp Communication and the Simultaneity of Opposites
}

\author{
by Alex Pillen
}

\begin{abstract}
A disregard for human traditions, the brutality of predation, sacrifice, and sexual desire are ingrained in languages across cultures. This paper concerns a key linguistic feature reflecting this predicament: utterances that encapsulate their opposite and effectuate a U-turn in meaning. This mode of communication stands out as a representation of the friction between incommensurable worlds - conceived together. An enemy's perspective or an unpalatable reality finds a host within language. I embark upon a multidisciplinary search for examples of such utterances and present an assemblage of five pertinent images. Each of these makes a distinct conceptual contribution. Vigilance and an awareness of other points of view underpin most of the utterances under study, which I propose to call "sharp communication" at the intersection of opposing perspectives.
\end{abstract}

In life, Ashe was afflicted with unreality, as so many Englishmen are; in death he is not even the ghost he was in life. (Borges 1944:10)

In London, in a home provided by the housing authority, Lorîn narrates an encounter that took place over a decade ago in Turkey. This story, told in Kurdish, is fast paced and exhaustive, and it documents her former husband's experience. He let Lorin know that he met his torturer-a policeman-in person, unexpectedly. He had taken the stairs to the tenth floor of a high-rise building to redecorate a flat. That is where he met the man, who had subjected him to the kinds of sexual torture that had made any future form of family life impossible. Lorîn enunciates a minute-by-minute account, reporting the speech and gestures of both men. Her ex-husband told her, "His color changed. I gave him my hand. I said 'hello' [to the torturer], the man's hand was trembling in my hand. Alone, they are always like that, when they are together they are like wolves, when they are left alone they get frightened." The two men engaged in a conversation. The handshake and the image of one hand trembling in the other conjure opposing worlds: a reassertion of humanity through ritualized gesture, while being horrifying at the same time. Like animals, wolveswhen-together, they become humans when singled out: "I gave him my hand."

In this paper, I explore the antithetical worlds encapsulated in this moment. I engage in a cross-disciplinary search for the linguistic counterparts to this kind of gesture. I mobilize the term antipodal to refer to the simultaneity of opposing worlds.

Alex Pillen teaches linguistic anthropology in the Department of Anthropology at University College London (14 Taviton Street, London WC1H 0BW, United Kingdom [a.pillen@ucl.ac.uk]). This paper was submitted 17 VI 15, accepted 14 VII 16, and electronically published 6 XI 17.
The term is derived from the Latin antipodes, or "those who dwell on the opposite side of the earth," and from the Greek antipodes, "with feet opposite (ours)." Or, in John Trevisa's translation of Bartholomew the Englishman's De Proprietatibus Rerum from 1397, "the antipodes, men that haue theyr fete ayenst our fete" (Bartholomeus 1535 [1240]:xv). This study of antipodal expressions emerges from anthropological work on dehumanization and the reassertion of humanity in contexts of extreme violence and civil war. The interface or shared boundary of the human and inhuman thereby becomes a point of departure to question words that contain their opposite and embody a U-turn in meaning: antipodal utterances.

\section{First Image}

\section{The Dictionaries of the Wolf-the Tiger-the Jaguar}

Anthropological debates on the intertwining worlds of humans and animals appear like an apposite point of departure to begin to define antipodal utterances. Relevant seminal texts mostly appeared in the 1980s and were based on research in Papua New Guinea, Central America, Malaysia, and Amazonia (Descola 1986; Howell 1984; Rappaport 1968; Schieffelin 1987; Severi 1982; Viveiros de Castro 1986; Wagner 1977). ${ }^{1}$ Further publications by the same authors as well as recent discussions were devoted to the study of ontological categories, such as "humanity" or "animality" (e.g., Kohn 2013). What used to be the philosophical study of the nature of existence and the dif-

1. Such key texts are to be contextualized within a wider array of ethnographic commentaries on comparable cosmologies in South America (Vaupes area, the Wari, the Juruna, Campa, Matsiguenga, Wayapi, U'wa, Akuriyo), Siberia, Asia (Chewong, Ma'Betisek), and native North America (Eskimo, Cree, Ojibwa, Koyukon, Kaska, Tsimshian, Haida; see Viveiros de Castro 1998b:471, 484). 
ferent categories of being - or ontology_-became a focal point of ethnographic practice. This opened the door to a consideration of the differing ontologies of contemporary huntergatherers: the definition of entities that exist or can be said to exist, and how they can be grouped as humans, animals or spirits. I propose to consider the linguistic dimensions and implications of such scholarship as a heuristic device to project a first image of antipodal utterances.

The anthropological literature includes valuable data on language practices in societies that do not feature modern distinctions between humanity and animality. Among the Kuna of Panama, humans and animals (although physically different) share a cultural prowess, such as the development of marriage customs and languages. Humanity does not occupy a privileged position in the world because of the existence of "language," as it does among us. The Kuna shaman is, however, the only human who knows the languages of animals, such as the call of the jaguar, and understands his speech (Severi 1982: $44,55)$. Likewise, in the tropical forest of the Malay peninsula, Chewong society stretches far beyond the ontological frontiers of "humanity" and includes spirits, plants, and animals, all with a reflexive consciousness, whether they be human or nonhuman. Each consciousness has a characteristic mode of vision, a different way of perceiving reality, portrayed by Howell as a "relativity of perception." Some spirits feed on the consciousness of humans and animals but perceive this as meat. Likewise, in the eyes of a tiger, humans are nothing more than potential meat, just as monkeys are to humans. There is a uniquely human way of seeing the world, but there is also a tiger's manner of seeing the world (Howell 1984:104-105, 156, 160-164). This is not an exceptional ontology found in Southeast Asia, and the same kind of "perceptive realism" can be found in Amazonia and Papua New Guinea. Multiple worlds coexist within the same environment, inhabited by classes of beings that perceive their fellows as humans but regard the inhabitants of other worlds as animals or spirits (Descola 2013:24). I set out to address how such ontologies are reflected linguistically.

With respect to Amazonian cosmologies, this carousel of perceptions has been labeled "perspectivism" (Lima 1996; Viveiros de Castro 1996). Among the Araweté, a Tupi-Guarani people of Brazil, animals and spirits see themselves as humans, and animals (as predators) see humans as animals (prey). Such Amerindian perspectivism has an essential relationship with a hunting ideology, and many of the examples given in Viveiros de Castro's work pertain to the semantic field of predator-prey relationships. The dictionary of the jaguar also contains the concept of manioc beer, and it has the same signification as in a human dictionary - a tasty and nutritious liquid that makes you drunk-but jaguars use it to refer to what we call "blood" (Viveiros de Castro 1998a:18, 22, 1998b:470). This is an image of a sign or words - manioc beer - that emerges from the study of Amerindian perspectivist cosmology. Viveiros de Castro states such findings call for a theory of the sign rather than a psychological study of animism or the attribution of a soul to a wider category of beings (1996:126, 1998b:476; see also Taylor
1993:444-445). I propose to define "manioc beer" as an antipodal utterance: a tasty liquid that may refer to the death of prey, including human prey, or blood. This example speaks to realities of dehumanization where the blood or suffering of a human being can be something pleasurable.

What is more, Viveiros de Castro argues that Amerindian words, which we usually translate as "human being," function as pronouns rather than nouns (e.g., us and them). They are not self-sufficient substantives but depend on a point of view. The fact that they were congealed into a noun, or "name of a tribe," appears as an artefact of the colonial encounter. The terms that refer to peoples denote human beings if uttered by humans, but if monkeys or beavers use them, they refer to monkeys or beavers (Viveiros de Castro 1996:125-126, 132, 1998b:476). Benveniste highlighted how pronouns such as "I," "you," "us," and "them" depend on the position and perspective of the person who utters them. This is a typical attribute of indexical signs or shifters. ${ }^{2}$ Each has its own reference, and this depends on the context of their use. Note that this is very different from a "nominal sign," defined by the object it refers to (e.g., a "baton"). There is no real object definable as "I" or "that." Such words lack material reference points. They have no value or do not exist, except in the instance of being spoken. Their meaning or referents depend on the moment they are uttered. Benveniste defines such words as an ensemble of empty or mobile signs that are nonreferential with respect to reality but can be filled in by a speaker. Pronouns are therefore words of an entirely different nature and escape the status of other signs of language. Language puts forth empty forms that each speaker can appropriate as relating to his person (Benveniste 1971:218-220, 226, 227). Viveiros de Castro argues that, among the Araweté, a wider category of words can function as pronouns, at least compared with IndoEuropean languages. The same pronominal principle applies to words that we translate as "human being" but also to words for bodily attributes or food- "manioc beer." "When uttered by a human or a jaguar, a man or his predator, they stand for very

2. The terms of this debate fit within the wider context of the study of indexicality, deixis, and shifters. "Indexicality" concerns meaning that depends on the context of the utterance. It is often used interchangeably with "deixis," which in the past was specifically associated with spatiotemporal references (e.g., "here" or "now"). "Shifter" is another word for indexical signs whose reference "shifts" regularly, depending on the factors of the speech situation. The referential value of a shifter therefore depends on an actual speech event (Hanks 2001; Silverstein 1976:24-25).

3. Taylor links the uncertainty, ignorance, and hesitation of Achuar peoples when faced with questions by anthropologists to this linguistic conundrum - the "substantification" induced by ethnographic (nominal) representation and translation (1993:444-445). In later work, Viveiros de Castro explores the limitations of our grammatical categories. Named artifacts are objects that necessarily point to a subject (naming them). Substances named by substantives like "manioc beer" are somehow used as if they are relational pointers, "something halfway between" a noun and a pronoun, a substantive and a deictic (2004: 471-472, 476). 
different things. This concerns purely pronominal forms of representation (Viveiros de Castro 1996:127-128).

Lima's analysis of Juruna perspectivism evokes its linguistic facet eloquently. The word is "nothing but anticipation." In the life of the hunter, not even the word is representation. The hunt can be seen as two simultaneous events: one event from the point of view of the human and another from the wild boar's perspective. They reflect each other. The word is a performance, intended to move from one perspective to the other-during the simultaneous events of the hunt-circulating among all perspectives and stopping nowhere. The word is hunting, anticipating, or tracing its double (Lima 1996: $35,41)$.

As suggested by a reviewer, Bachnik's work on "situated meaning" is useful here. The argument above is affected by a tension between terms derived from Indo-European grammar (Benveniste 1971) and an Amerindian language from an entirely different family. Bachnik's linguistic anthropology of Japanese accentuates the preconceptions ingrained in the grammar of European languages. Personal pronouns, such as "I," "you," and "she" are imbued with the ancient Greek notion of dramatic character or theatrical role (via the Latin per sonae, meaning that through which the sound comes, or mask; Bachnik 1982:3). The use of the term person or personal pronoun by grammarians is therefore related to their metaphorical conception of a language-event as a drama in which the principal role is played by the first person, the subsidiary role by the second person, and other roles by the third person (Lyons 1977:638, quoted in Bachnik 1982). In Japanese, the situationally located relationships between speaker, hearer, and their scene displace the notion of language as a classical dramatic event. Situated meaning is not "about" an external world. The organization of the Japanese language around situated meanings is at odds with the notion of an external nonlinguistic world reflected in referential language (Bachnik 1994:23; Brenneis 1994:x). It is as if a language-event conceived as drama engenders wider viewpoints beyond the immediate situation or an external world to be venerated via referential language use. By contrast, Bachnik notes that "Most linguists agree that no class of pronouns exists in Japanese, and that names, age-status terms, kin terms, place-names, and zero terms are all used where pronouns would be used in Indo-European languages" (1986:56). Moreover, the situated meanings of Japanese words that we do not intuitively classify as pronouns accentuate the conceptual conundra that also affect the material on Amerindian languages quoted above.

Another central example can be found in the work of Erikson or his analysis of the word nawa among the Amazonian tribes that make up the Pano linguistic group. Nawa is a generic term for stranger, but it also features in names used by people to refer to themselves. It designates both that to which one is opposed and that with which one identifies. Erikson defines nawa as a kind of reservoir of brute force that needs to be socialized, but it is also defined as a model or even the guarantee for the virtues that constitute society. He highlights the remarkable ambivalence of the concept nawa. Alterity, even radical alterity, is perceived in a paradoxical manner: as being consubstantial with the self (1996:78-81). Descola quotes Erikson's work and remarks: "It is here that the theme of perspectivism developed by Viveiros de Castro acquires its full meaning." The antipodal word nawa can therefore be found in societies that are not perspectivist in the narrow sense of the word, where it is not claimed that animals, who see themselves as humans, apprehend humans as nonhumans. This concerns a wider category of societies, defined by Descola as seeing oneself through the eyes of another-through the eyes of external observers, other tribes, other species, or the dead. A point of view, different from their own, becomes indispensable to situate themselves in their own collective (Descola 2013:255-256). This analysis highlights the wider relevance of Viveiros de Castro's call for a theory of the sign, beyond the study of a smallish number of societies that are defined as perspectivist in anthropological parlance (Viveiros de Castro 1998b).

A cross-examination of the substantive in our translation of Amerindian languages and Benveniste's notion of the empty sign are leading tropes for the study of the antipodal utterance. For the time being, the space that will never be filled, or the paper's title, denotes this kind of emptiness. The field note I cited in the introduction, about a man and his torturer, leads me to juxtapose the notion of the wolf to the well-known examples of tiger and jaguar and to extend this discussion to a wider category of dehumanized humans and enemies in opposing contexts. To complement this image of antipodal utterances depicted so far, I now turn to an Indo-European world, or historical and linguistic material on chronic warfare and conquest in ancient India.

\section{Second Image}

\section{The Gap between the Beginning of a Step and Its Completion}

Modern translation and the language we use to discuss linguistic practice globally - our metalanguage - might not be sufficient. I now consider the metalanguage of the Sanskrit scholar Pānini as a second heuristic device to study antipodal utterances. His grammar is one of the earliest known works in descriptive linguistics, from the fourth century BC. ${ }^{4}$ Renou explains how the vocabulary of that era included twin formula or positive and negative phrases that were mentioned together and eventually consisted of one expression. Such contrasting formulas occurred with a remarkable frequency. There was an excess of words with a double meaning in the Sanskrit literature, as words moved from one pole of the semantic scale to the other via intermediary meanings. However, Renou highlights instances of "radical semantic rupture" and argues that "banal euphemisms" are to be distinguished from words that

4. Pānini described a $b h \bar{a} s ̣ \bar{a}$, a spoken language as well as the religious language of Vedic India (Renou 1941:106-107). 
effectuate a U-turn in meaning. He offers a critique to colleagues who are prone to explain such contradiction with reference to the notion of euphemism. Verbs referring to violence had a natural ambivalence, as one verb could have both a violent meaning and its opposite (see table 1). The same words were often used to refer to both allies and enemies. Renou translates the Sanskrit yakșá as both prodigy and misdeed and warns us against the inexact modern translation "demon" (Renou 1939:163, 167, 174, 176-177, 187, 195, 205). These are Sanskrit words that I propose to call antipodal.

Malamoud's work on ancient India points in a similar direction. Vedic thought accentuated the significance of the difference existing between superimposed meanings. An enigmatic word might draw its strength from the tension of the question to which it gives rise or the space opened up by this question. This constituted a suspended betweenness or a space that will never be filled (Malamoud 1996:206). ${ }^{5}$ As the title of this paper suggests, I propose to retain this as a key phrase for this study of the antipodal utterance. It is a space seldom inhabited by the modern scholar, and I deploy it as a critical vantage point for a probe into each of the five selected images.

An indispensable point in Renou's study is that ambiguity does not essentially occur at the level of the word but exists as a more fundamental ambiguity. Within Vedic thought, things in the world or the referents themselves can be ambiguous. Renou's detailed analysis of ambivalence in the names of weapons, enemies, allies, and populations leads to an understanding of the political circumstances surrounding the cultivation of such an ambiguous vocabulary (Renou 1939:203216). The superposition of two contrasting values within one term exists not only at a linguistic level but within the acts themselves. Given the volatile political context of Vedic India, uncertainty and flux were sedimented into language. The indeterminacy engendered in the phenomenon of switching sides manifests itself within language - a man of the clan or a man who now belongs to the enemy. Renou thus stresses there is a reversibility of the acts as well as of the formulas describing them.

Such expressions are radical in the sense that they recognize the presence of different perspectives_-"reconnaissance d'une contre-partie," in Renou's words. Renou stresses that the sociopolitical conditions of the Vedic era explain the importance of such linguistic couples. This is conceptualized as a reciprocity or equilibrium in the use of weapons and violence as well as speech by the two opposed parties. In other words, meaning emanates from a particular perspective and position within the political context, but such positions can rapidly shift

5. This is an image readily depicted by a Japanese term for which there is no English equivalent. $M a$, or "negative space," denotes a gap, a space between two structural parts, the void between objects, an interval-a simultaneous awareness of form and nonform. Hladik translates it as espacement in French. She also pays attention to words such as ko-rai (the past-future), sho-ji (birth-death), or shometsu (birth-disappearance): linguistic couples that are inseparable, where opposites meet (Hladik 2008: 177-178, 221). and give way to an opposing perspective and concomitant value of actions and moves. An ambiguous vocabulary is the linguistic counterpart of a worldview in which it is not so much the values of words that are reversible but the value of the actions they describe, actions that are likely to occur simultaneously within the worlds of opposing camps (Renou 1939: $212,222,229-230,232)$. This is equally important in VidalNaquet's work concerning ancient Greece. The ambivalence of efficacious speech in the most ancient works of Greek thought was preceded in the classical city by an ambiguity of action, or the permanent risk involved in every collective decision. One's acts might become something different due to the indeterminacy of collective action. A simple land clearance might actually be a full colonial expedition - peace or war (1996: 11). ${ }^{6}$ Here the referent itself is unpredictable and therefore ambiguous.

Our modern experience of such linguistic realities appears governed by notions of the enigmatic, the contradictory, or even the mysterious. The metalanguage of the Sanskrit scholar Pānini enables us to depict a more focussed image of such words. Renou's analysis of Pānini's grammar considers the status of the noun or substantive in ancient India. A first question, of course, is how Sanskrit scholars conceived of the notion of the "word" itself. Renou locates the origin of Pānini's grammar in Vedic ritual, as many key grammatical terms were borrowed from ritual language. The grammatical term "word" was derived from the ritualists' concept of "step." Renou points out that the hasty transcription of Sanskrit grammar "into modern" by nineteenth-century scholars makes us loose sight of the ritual philosophy inherent within Sanskrit grammar. ${ }^{7}$ The concordance between the linguistic habits of ritual and grammatical theory reveals that both disciplines emerged in the same milieu and responded to complementary sociopolitical needs (Renou 1941:134-137, 144, 152, 160). The image Pāninii's "word" conjures appears to acknowledge an intermediate zone, or the indeterminacy between the beginning of a step and its completion. The image of a footstep appears complemented by a modern description of "a suspended betweenness" or space that will never be filled (as in Malamoud 1996).

Renou's seminal work opens up the possibility for a further consideration of sacrificial ideology to question antipodal linguistic form. Not only was the notion of the "word" initially

6. Detienne's work on ancient Greece gives a detailed image of the cognitive processes whereby ambiguity was replaced by a differing mode of thought favoring noncontradiction. He questions what mental structures link a logic of ambiguity and a logic of noncontradiction and argues that ambiguity - in the sense of an intermediate zone between antithetical terms - has not been totally expunged (Detienne 1996:17, 86, 106, 125, 127).

7. See Hastings's "From Ritual to Grammar" for a further discussion of Vedic literature, the structure of ritual manuals, as well as metalinguistic devices in Sanskrit grammar (Hastings 2003). Also see Robbins for a consideration of the link between conceptions of language and ritual and the relationship between linguistic and ritual ideologies (Robbins 2001:598). 
Table 1. Elements revealing a fundamental ambiguity or slippage in meaning within the vocabulary of the Rigveda, giving abbreviated descriptions of semantic fields followed by a column with direct quotes or supporting data from Renou's oeuvre

\begin{tabular}{|c|c|c|c|}
\hline & Favorable semantic zone & Unfavorable semantic zone & Renou (1939) ${ }^{\mathrm{a}}$ \\
\hline vrj- & $\begin{array}{l}\text { To overthrow the malicious } \\
\text { ones, to divert maleficent } \\
\text { beings }\end{array}$ & Curve, sin, wrongdoing & $\begin{array}{l}\text { La racine } v r j-\text { possède une double valeur très } \\
\text { accusée. D’une part c'est 'renverser' les } \\
\text { méchants. (cf. la spécialization péjorative prise } \\
\text { par vrjiná- 'courbe, faux' et même 'péché' } \\
\text { en class., 'détresse' Bhāg. Pur., comme áṃhas- } \\
\text { támas- bhādá-). D’autre part 'attirer à soi (la } \\
\text { divinité).' Si l'on fait entrer en compte l'usage } \\
\text { des Br. Ge. VSt. I p. } 152 \text { et notamment } \\
\text { l'expression pāpmānam vrj- 'détourner le mal', } \\
\text { la rupture sémantique est à son plus haut } \\
\text { point (176). }\end{array}$ \\
\hline saścire and saścima & $\begin{array}{l}\text { Us the pious ones who } \\
\text { escape them }\end{array}$ & $\begin{array}{l}\text { The man who was conquered by the } \\
\text { empire of the malicious ones and } \\
\text { has left our community }\end{array}$ & $\begin{array}{l}\text { Ápa saścire V } 202 \text { se dit de l'homme qui tombe } \\
\text { sous l'empire des méchants, qui quitte la } \\
\text { communauté: mais la variante ápa ... saścima } \\
\text { au même passage dans le YV. utilize une } \\
\text { acception inversée 'nous (les pieux) qui leur } \\
\text { échappons' (O.): on voit avec quelle facilité } \\
\text { une même combinaison linguistique se prête } \\
\text { à fonctionner dans les directions opposées } \\
\text { (171-172). }\end{array}$ \\
\hline jána- and jánya- & The men of the clan & $\begin{array}{l}\text { Strangers, belonging to the enemy, } \\
\text { a foreign country }\end{array}$ & $\begin{array}{l}\text { jána- désigne les hommes du clan (auquel } \\
\text { appartient celui qui parle); au contraire le } \\
\text { dérivé jánya- signifie 'étranger' dans jányād } \\
\text { áṃhasah IV } 555 \text { opposé à mitríyāt, sans } \\
\text { doute aussi IX } 49 \text { 2. Plus nettement jánya- } \\
\text { X } 42 \text { 6, épithéte de dyumná, est 'qui appartient } \\
\text { à l'ennemi'... Quant au mot jána- lui-même, } \\
\text { le sens correspondant 'pays étranger' n’y est } \\
\text { pas inconnu: PB. VI } 1012 \text { XVI } 68 \text { Caland ṢB, } \\
\text { p. } 197 \text { Eelsingh (et cf. Caland Ai Zauberei } \\
\text { p.6 n. 36) Saundar. XV } 31 \text { et skt boudhh en } \\
\text { general (207-208). }\end{array}$ \\
\hline
\end{tabular}

${ }^{a}$ Please note the date of publication of this text by Renou, which I mobilize in dialogue with later work by Malamoud (1996). Since 1939, there have been major developments, not least the first complete English translation of the Rigveda in over a century, by former students of Stanley Insler (Jamison and Brereton 2014). Insler comments on Renou's article from 1939: Renou "overlooked that the RigVeda, although a text in praise of good gods and their abilities, also has to mention the bad gods and their followers. Since there were no separate vocabularies for these opposing sides, the same terminology had to come into play from time to time." Regarding one of the entries in table 1, Insler comments "there is no other way to express the sentiment" and notes that other old Indo-European languages have distinct vocabularies for such purposes. Avestan, the closest sister language to Sanskrit, has a completely different vocabulary when speaking of the followers of truth and the followers of deceit (S. Insler, personal communication).

derived from the religious concept "step," but a ritual's sacrificial substance (dravya) acquired the meaning of "substantive" in Pāninii's grammar. The attraction of meaning from a preceding enunciation was also encoded in grammar (e.g., as anukarșaṇa in the work of Sanskrit grammarians Kātyāyana and Patañjali). Within the commentaries on Vedic ritual, this is ordinarily expressed as äkarșana (Renou 1941:125, 140). Here I am compelled to refer to the Sanskrit term's contemporary use by ritualists in Sri Lanka. Note the modern interpretation of äkarșana, as Obeyesekere translates this term as "magnetism" (1984:108). During sacrificial rituals, illness or moral faults are transferred from the patient into a sacrificial object in an act of cleansing (Argenti-Pillen 2007:119-122, 2010:119). The term äkarșana denotes the effect of circular gestures. They attract faulty moral substance or illness and transfer it from the afflicted person into the sacrificial substance. The sacrificial object thereby contains or encompasses the cause of illness and disorder. It is subsequently offered to the offending spirits, who are tricked into consuming and containing the illness they caused. Agents of illness consume the faulty moral substance and thus attest to their reversibility. ${ }^{8}$ The grammar of a sacrificial gesture (or ākarșaṇa) and the ritual steps taken to constitute the sacrificial substance give an indication of its antipodal character, simultaneously embodying disease and constituting its remedy. Much like an utterance can attract meaning from a preceding utterance, ritual gestures attract moral substance into a sacrificial object. Renou's ma-

8. Such sacrificial practices are embedded within a wider cultural context of cultivation of ambiguity and encompassment of opposing elements. Kapferer highlights the ambiguous and unstable character of deities and demons within the Sinhala Buddhist pantheon, as forces of relative purity and fortune are inextricably linked with the forces of pollution and death (Kapferer 1983:163-164). 
terial on sacrificial substance and the concept of the "substantive" in ancient India (1941) as well as the notion of a karsana in recent ethnographic work point at the relevance of the study of ritual for the study of the antipodal utterance and "substantive." The ethnographic study of sacrificial ritual forms the basis for the next image of the antipodal utterance.

\section{Third Image}

\section{Sacrificial Substance-the Substantive-Simultaneity}

Anthropological scholarship on sacrifice and divination allows me to superimpose a third image and analytical milestone. Devisch, in a monograph on Yaka culture in the Democratic Republic of Congo, provides a fundamental example when he addresses the ambiguity of the term fula. This word refers to the root cause of affliction - a condemned misdeed or theft within the community, but also the foam and sediment that emerges during the fermentation of palm wine, the erotic attraction between partners, and finally the appeal or attraction between healer and patient (Devisch 1993:11, 230, 268; R. Devisch, personal communication). As such, the word fula completes a U-turn in meaning. A similar dynamic governs the blood sacrifice of the hen. The healer coils a hen in a spiral around the patient's body and thereby transfers the patient's illness to the sacrificial bird, before it is consumed by members of the group. As both substance of affliction and force of healing, the sacrificial hen fits within a wider Yaka cosmology in which ill fortune and disease can be induced to destroy itself. The process of healing in Yaka culture is thus understood as an ability to simultaneously embody and enact strongly conflictual affects and contrasting states of life. Ritual corporeal devices engender the simultaneous deployment of one connotation and its reverse in a conceptual realm where separateness and interdependence, autonomy and mutuality exist simultaneously. ${ }^{9}$ Devisch depicts such ritual reversals as realities not yet appropriated by a hero, an author, or the leadership of a narrative voice (Devisch 1993:212, 236-237, 242, 253-254, 266, 269) - in my analysis, a reality not yet appropriated by a perspective.

Renou attributes antipodal structures of meaning in ancient India to the indeterminate sociopolitical circumstances of Vedic society (Renou 1939). Devisch, however, relates the basic ability to embody paradox, bipolar unity, oneness, and duplication to everyday experiences of life transmission: the solidarity between life giving and death and the risk of death in child birth. The ambiguity and risk of life transmission fits within a wider category of double-bind experiences, as people are trapped between the contradictory constraints of fidelity to tradition and the concrete demands of survival. In the ethnography by Devisch, "Janusian" refers to the ability to conceive and use multiple antithetical or opposite thoughts simul-

9. Different from the nonparadoxical logic of distinct "binary oppositions" (Devisch 1993:276). taneously. A world of "simultaneous identification" emerges. A bridge between polar opposites reflects a Janusian world and thought movement where strongly conflictual affects are simultaneously embodied (Devisch 1993:266, 269-270, 274-275, 277). This study attests to the value of an analysis of sacrificial ideology and double-sided realities in healing rites for a more general consideration of antipodal forms of expression.

Antipodal utterances reveal a culture-specific pattern of meaning - as opposed meanings may be encompassed by a single word. The Bakhtinian notion of "shared territory," developed by Brenneis, leads to the image of the word as locality with a culture-specific configuration and boundary of meaning (Brenneis 1986:339). This allows for an exploration of spatial images of the word: the word as a space within which signification articulates itself. Antipodal words are characterized by a tension between opposing meanings, a "grammar" internal to the word or inner tension, which is not reducible to the notion of polysemy. Inhabiting this space involves a sensibility to an enigmatic affective state, in which emotions are suspended between opposing poles. A Bakhtinian dialogism (cf. Kristeva 1980:74) inherent in the word takes into account an orientation toward the other, the interlocutor. The literary word is seen as "an intersection of textual surfaces rather than a point" (Kristeva 1980:65, emphasis in the original). This imagery, however, is based on a subjectivism of authorship and interlocutorship. Note that Bachnik's analysis of Japanese discourse points at the cultural limits of an Indo-European pronominal paradigm or "shifting" between the perspectives of speaker and addressee - the pronominal "I" and "you" as focal poles of interaction and dichotomy of self and other (Bachnik 1982:15, 23-24, 1986:56, 68). I postulate that dialogism and the sharing of territories of meaning are different from inhabiting the tension between opposing meaning in a preauthorial (Devisch 1993), anticipatory (Lima 1996), or perspectival (Viveiros de Castro 1996) sense.

Antipodal words challenge the taken-for-granted margins of semantic networks or include points of semantic rupture. By taking into account Mary Douglas's approach (1966:122-125), the boundaries of the word as territory can be interpretatively linked to other spatial idioms - in this instance, sacrifice and sacrificial substance. The topography of the word, or texture of meaning, may include its opposite. The image of encompassment of opposites I depicted in this section depends on examples of sacrificial substances as well as "substantives," such as the word fula in the work of Devisch. As a container of opposing meaning, a center of an antipodal word is difficult to define. Opposing meanings do not coagulate to make a stable core. The image of an outer shell, emptiness, or a tension of meaning emerges, characterizing the semantic topography of the antipodal utterance: a space that will never be filled.

This third image of the antipodal word depicted so far depends on a simultaneity of opposites. The notion of simultaneity merits further attention. Parkin's analysis of the speech of Arab, Swahili, and Giriama diviners of Kenya addresses "cognitive simultaneity": speaking and thinking of different 
events as if they occur simultaneously, even in contradiction. This concerns the thought process, reversal, and contradictory simultaneity in the speech of a diviner. Conflicting innuendos are created, so that diviners can retreat from an unpromising lead and take up another through the use of the same words. Parkin quotes a diviner addressing a client: "But the wife can't or won't get out of your body . . . and she can say I don't love you and she can leave you." It is noteworthy that the wife is locked inside the victim's body, possessing or consuming it, yet she is also leaving it. Parkin concludes that this logic of simultaneity achieves a shocking and brilliant poignancy that conventional sentences rarely attain. This logic operates at a level closer to the orderless networks of deep-structure semantics and aesthetic of ritual and is to be distinguished from the sequentiality of other forms of language. This analysis of the logic of simultaneity in divination, as including contradiction and some reversals, includes references to what I would call antipodal sensibilities $(1982: 71,74,78,82-83) .{ }^{10}$ Parkin's juxtaposition of the conventional versus the brilliantly poignant and the simultaneity of opposites in Giriama divination highlight the relevance of an anthropology of religious practice for the study of nonsequential dimensions of language.

Quintessential topics of anthropology_-sacrifice and divination - offer a tool to question the analytical preponderance of pronominal forms of representation: the relative value of a pronominal paradigm and its sequential habits. First, Renou's findings resist analysis in these terms. He highlights the perspectival quality of certain Sanskrit words but encounters a firm ground in Pāninii's grammar. The notion of dravya or sacrificial substance is adopted by Sanskrit scholars to mean "substantive" or noun. In this paper's succession of images, a consideration of nouns that may be functioning as pronouns gives way to a study of the antipodal noun itself. Seminal work by Parkin (1982) and Devisch (1993) addresses the simultaneity of opposites within an anthropology of sacrifice and its vocabulary, divination, and the aesthetic of ritual. As this paper's subtitle indicates, a simultaneity of opposites is a defining element of sharp communication piercing through a sequential logic of representation. This third image leads me to direct my attention to the history of English literary aesthetics in a fourth and penultimate image.

\section{Fourth Image}

\section{The Blank Cheque of Paradox}

One might argue that the contradiction merely supplies the tension, and does not decide the note on which the string will vibrate. (Empson 1951:12)

10. Parkin states that Ardener's (1971) analytical priority was not the word "witch." For him, this was only a curtain between acts in the ongoing drama of how to deal with disaster: a simultaneity of allusions, and parallel innuendos, cross-varying perspectives that eventually come together in the word (Parkin 2015:5-6).
A General Theory of Magic - one of anthropology's canonical texts - emphasized ambiguity as the remarkable feature of ritual and other ways of creating "magical" forces. A representation that is singularly ambiguous lies at the basis of magic (Mauss 1950:107). Lévi-Strauss focused on certain linguistic features, which Mauss did not fail to notice. Mauss, however, did not "make as much of them as he should" (Lévi-Strauss 1950:49). Lévi-Strauss notes that many Papuan and Melanesian languages have only one word to designate buying or selling, lending and borrowing. Antithetical operations are expressed by the same word, indicating a reciprocal relationship. LéviStrauss further considers a semantic function, whose role is to enable symbolic thinking to operate despite the contradiction inherent in it. He addresses the insoluble antinomies of certain words and notions, or the fundamental contradictions "which struck ethnographers so forcibly" (1950:63-64).

William Empson's oeuvre allows us to bring home such debates to a European context of literary criticism. In his analysis of forms of ambiguity in the English literary tradition, he defines a seventh type of ambiguity: when the two meanings of a word, the two values of the ambiguity, are opposites. Among illustrations of this seventh type from four centuries of English poetry, Empson invokes "primitive" languages but adds that "there seems nothing peculiarly primitive about the sentiment" and "identity of opposites." ${ }^{11}$ He mentions that early Egyptians apparently wrote the same sign for "young" and "old." He cites the Latin altus, high or deep. Other examples are from a more recent era. He considers Arabic a striking case of the mental sophistication required to use a word that covers its own opposite. Such words are considered to be of a late origin and were elaborated as a literary style. Likewise, the many English examples are all later developments. For example, the English "let" as "allow" or "hinder," and "prone" as either "active," "tending to," or "inactive and lying flat" in retirement or with a lover. Empson defines the notion of "relational opposites," which very much speaks to the realities addressed in the work of the Sanskritist Renou: "to know what a ruled person is you must know whether the ruler is a general or an archbishop. Thus a word, which names both parts of a relation, may be more precise than a word, which only names half of it" (Empson 1930:192, 194-195).

Empson concludes that, though such words appeal to fundamental habits of the human mind, they are to be expected from a rather sophisticated state of language and feeling. This seventh type of ambiguity is a powerful literary weapon among the English, reflecting either a contradiction of thought or a contradiction of feelings and impulses. To discover what shade of interpretation is put on "the blank cheque of a paradox" defines the meaning of the verses Empson addresses (Empson

11. This concerns the work of Edmund Spenser (1552-1599), William Shakespeare (1564-1616), John Donne (1572-1631), George Herbert (1593-1633), Richard Crashaw (1613-1649), John Dryden (1631-1700), John Keats (1795-1821), and A. C. Swinburne (1837-1909). 
1930:210). For "complete examples" of this seventh type, there needs to be an impulse to state two opposites defined by their contexts and a collision of a genuine pair of opposites. A violent and deep-rooted ambivalence, or two systems of judgement, are forced into open conflict before the reader. This is sometimes achieved by successive fireworks of contradiction and a mind jumping like a flea. Empson highlights how Keats often used ambiguity of the seventh type to convey a dissolution of normal experience into the intensity of sensation. Examples from Crashaw reveal how the religious and the sexual are both contexts that define the opposites. This seventh type of ambiguity is about finding a narrow border of experience that both hold in common-using one as a metaphor for another would be an ambiguity of another type. The seventh type stands, as it were, for the point of friction between two worlds conceived together. It transpires as a necessary method to deal with the most deeply rooted and complicated notion of the human mind. This notion of ambiguity constitutes a literary method that can address the experience of killing someone as well as sexual desire (Empson 1930:197, 201, 214, 218, 223, 226, 233).

Empson's Seven Types of Ambiguity thus provides a crucial point of reference to define antipodal utterances and modes of expression within our cultural heritage. This fourth image is determined by the friction between two worlds "conceived together" and the narrow border of experience that two incommensurable worlds hold in common, as evoked by the English. The terms of the debate here appear to conjure anthropological tropes rather than modern linguistics or even literary criticism: the dissolution of normal experience, the intensity of sensation. Indeed, this is a theme that resonates with this paper's introduction; Empson references "the experience of killing someone" or inhabiting a gray zone between inhumanity and humanity.

In The Structure of Complex Words, Empson introduces words that carry rival doctrines and defines words that have a very high degree of integration of their meanings. The latter include paradoxes, written via the formula $A=-A$. The function of such a paradox is to hint at some reconciliation that is otherwise ineffable. Moreover, it does not seem to be two ideas equated but one idea contradicted. Some words may suffer from a breakdown of reciprocity, as the word is to be used in one way about me and in another way about you. Empson provides examples of a general "trick of the mind," which he finds among individual theorists and (literary) stylists rather than in common use. About Jane Austen's use of the word "sensible," he writes "the adjective was likely to be a no-man's-land between the two factions" (1951:30, 52-53, 59, 306). Empson pays tribute to Kenneth Burke (1941) but comments "he was not as I understand it thinking of the analysis of single words." Empson does, and the movement he has in mind is simply "a narrow thing within one word" (1951:66; see also 347, 350, 386).

Here it is important to recollect the second image I depicted or, more generally, Renou's contribution. Empson alerts us to a word's value being applied to both of two opposite extremes, and here he revisits the idea of a word used as a "blank cheque" (1951:313). Empson adds:

The most striking recent work on the kind of linguistics I am trying to consider here has been a very untechnical one; it is in the dreadful book 1984 which George Orwell wrote while dying. What he calls "double-think", a process of intentional but genuine self-deception, easy to reach but hard to hold permanently, really does seem to be a positive capacity of the human mind, so curious and so important in its effects that any theory in this field needs to reckon with it. (1951:83, emphasis added)

This affordance of the human mind is also depicted by Empson as a vague feeling. A referent is often given a solid quality, and you can feel that the word somehow covers it. Still, is there more to it? For Empson, this kind of feeling is not merely primitive or illogical, but it keeps us in contact with reality. This becomes more acute when he addresses what I would call antipodal words. Empson's treatise on the English word "dog" leads him to a vision of the word that carries a duality of feeling or is a meeting ground of two rival theologies. Furthermore, for the purpose of rhetoric and in order to sound good, the strain may well need to be inside the words themselves. ${ }^{12}$ Most of our words, though, are dead symbols, only interesting in view of their referents (Empson 1951:387). Others are given a life of their own through literary practice over centuries (1951:158$184,317-318,354,387,430$ ).

In a crucial passage, Empson evokes the notion of pretence, which I propose to interpret as a kind of awareness. He states that rhetorical form is used for a form of pretence of false identity. A sentence is framed so that we realize how different its words would appear to the opponent. One may call this the device prior to irony that keeps alive both sides of the debate, or one might merely say that it invokes "the old magic." This, however, projects us beyond the definition of magic in anthropology cited at the beginning of this section. To keep alive both sides and give complex words a life of their own is the business of a writer (like Empson). If a dictionary is to seem more than a toy, a living dictionary ought to be written that brings to life complex words. It shows no respect to the living language to treat all words as rubble (1951:387, 390-391, 409, 412), and one but wishes Empson was around to treat us to a dictionary of the jaguar.

Empson had written the Seven Types of Ambiguity (1930) at the young age of 22. Serendipitous events soon after led him to take up a position in Tokyo and study Buddhist sculptures across the far East and South Asia for over a decade. The resulting monograph went missing just before the Second World War and became one of the great lost books, to be rediscovered only recently (Empson 2016). The mindset and

12. How far thought of this kind is expressed due to contradiction within single words (the topic of this paper), Empson does not pretend to decide, and much of it is clearly in the overt grammatical form A is B (Empson 1951:389). 
critical acuity of the Seven Types of Ambiguity, composed entirely on the basis of literary criticism of English poetry, now was transposed to the study of Buddhism and its cultural legacy. Empson proposed a close textual reading of Buddhist images and highlighted the dual significance of the face of the Buddha, as the right and left side revealed asymmetry and suggested contradictory moods, paradox, or conflicting spiritual and emotional states (2016:xiv, 72). I end this section with a quote from The Face of the Buddha, to illuminate the ethos of this paper and its five differing images. Here, radical cross-cultural theoretical engagement appears to be encompassed within the life of a single author-Empson. He writes about a Buddha: "the puzzlement and the good humour are all on the left, also the maternity and the rueful but amiable smile. The right is the divinity; a birdlike innocence and wakefulness; unchanging in irony, unresting in good works; not interested in humanity or for that matter in itself' (2016:100, emphasis added). I now propose to reflect on the notion of irony and indeed wakefulness or vigilance in the remaining sections of this paper.

\section{Fifth Image}

\section{Denunciation of the Substantive in Postmodern Cosmology}

Perspectivism was a term coined by Friedrich Nietzsche in The Will To Power (1910:20). I deploy the original German Perspectivismus to distinguish it from a contemporary anthropological usage of the term I discussed above. Perspectivismus also entails a deliberation on the status of the word: every instinct is a thirst for power, each with a point of view, and the word is but the horizon line of our knowledge, designating the limits of a perspective. Where our ignorance begins - at that point from which we can see no further-we set a word. Nietzsche considers our belief in the notion of "substance" to be a formulation of a grammatical custom. Our concept of substance - a very powerful faith - is conceived as an outcome of our concept of the subject. The subject connotes our belief in an entity underlying all the different moments of intense sensation of reality. We believe in our belief to such an extent that - on its account alone - we imagine "substantiality" (1910: 13-15). Nietzsche concludes that our ontological categories are illusions perpetuated by the chance subject/predicate structure and grammatical habits of Indo-European languages (Benes 2006:220). In other words, familiar categories of reality reflect a misplaced faith in our grammar. Note that Nietzsche argued that a modern metaphysics of language in the Indo-European tradition hides brutal realities governed by a will to power (Benes 2006:226-227). This is important, given this paper's subsidiary theme: being human in the face of inhuman brutality and reflecting such incommensurable worlds in language. Hence the paper's first image focused on Amerindian languages and the dictionary of the jaguar.

Perspectivismus encapsulated Nietzsche's theoretical endpoint of an embattled Euro-American cosmology (Nietzsche 1910:13, 20). The death of God and his concomitant universal perspective led to a reality molded through perspectival glimpses or multiple, fluid points of view. The perspectival character of existence in Nietzsche's oeuvre (Nietzsche in Williams 2001: $169,239)$ offered a gloomy forecast of a Euro-American postmodern culture or ironic condition. Nietzsche's doubt regarding Indo-European languages and a modern faith in substantiality provides a welcome supplement to the development of this paper, articulated in relation to both the pronominal paradigm of modern linguistics and a historical and ethnographic reflection on the notion of the "substantive." A Nietzschean tactic to question our faith in (modern) grammar leads me to consider postmodern cosmology in a final and fifth image of the antipodal utterance.

A focal point for the study of antipodal words in this culture is Kristeva's call for a linguistics other than the one descended from the phenomenological heavens. She brings together the notions of phenomenon - an observable reality experienced from the first-person point of view-and heaven, a key element of a Christian belief system. The episteme of modern linguistics therefore appears as a symptom of the drama experienced by the Western subject as it attempts to master and structure not only the logos but also its translogical breakouts. Kristeva notes that the adherence of modern linguistics to the phenomenological subject describes stability where one should acknowledge mobility, unity where there may be contradiction (Kristeva 1980:6, 27, 72, 146). ${ }^{13}$

Establishing a sign system calls for the identity of a speaking subject within a social framework, which is recognized as the basis for such an identity. At times of abrupt changes, renewal, and revolution in society, such bases for identification shift. Once the social framework with which one had formerly identified is challenged, the subject undergoes an unsettling process. A previously established sign system faces countervailing forces (Roudiez 1980:18, quoting Kristeva 1975). Kristeva includes such societal considerations in her analyses of the language of carnival, or what she calls a carnivalesque logic. Within the carnival, the structure of the author emerges as an anonymity that sees itself as self and other, or as man and mask. For Kristeva, the fundamental problem is to describe this other logic without denaturing it or appropriating it via an illsuited vocabulary. She proposes a "shift from subjectivism to ambivalence." Such an ambivalence is not only linked to rapid societal change and revolution, as highlighted above, but also the realities of death, birth, and sex (Kristeva 1980:74, 78-89)..$^{14}$ When literature touches upon such strategic points - at the very origin of the narration, at the very moment when the

13. The entity Kristeva posits as being anterior to any space, lacking a thesis or position, unity, or identity is often usurped by her notion of (Freudian) instinctual drives. However, Kristeva's work on the structure of poetic and carnivalesque language transcends this Freudian imagery and takes into account sociopolitical circumstances (1980:6, 72).

14. Kristeva notes that Bakhtin - born of a revolutionary Russiahighlights both subjectivity and intertextuality, a blurred subjectivity yielding to ambivalence (1980:68). 
writer appears - we experience emptiness: an anonymity, an absence, a blank space, Kristeva states. ${ }^{15}$

Such an emptiness is subtly different from the felt subjectivity inherent in Bakhtinian dialogism: the coming-andgoing movement between subject and other, speaker and interlocutor, or writer and reader in poststructuralist thought (1980:74-75). Kristeva introduces the almost counterintuitive notion of "the logic of nonexclusive opposition" to describe the ambivalent spaces within carnivalesque language (1980:72, 86). I propose to reiterate this as a logic in which each opposing social framework is not omitted from consideration or excluded. Ambivalence and nonexclusive opposition displace the imagery of subjectivism. Kristeva thus brings together many of the themes articulated by the authors I quoted to depict the previous four images of the antipodal utterance; death/predation, birth/survival, sexual desire, and political flux/revolution.

Deleuze's work has comparable implications for both subjectivity and modern metalanguage. He deconstructs the notion of an individualized form of a world, or world corresponding to individuals. Deleuze contemplates paradox or the event that moves in two directions at once and fragments the subject following this double direction. A Deleuzian image of subjectivity emerges as continuous displacement - as being always displaced in relation to itself. A subterranean principle of counter-sense is imposed on sense, in a world of disjunctive synthesis. Deleuze stresses this is not merely a reversal of perspectives but acknowledges the bidirectionality of this continuous motion. ${ }^{16}$ Such a postmodern cosmology and philosophy of language denounces the false simplicity of language and questions whether there might not be two languages and two sorts of "names," only one of them designating the pauses and rests, or even two distinct dimensions internal to language, when substantives and adjectives begin to dissolve (Deleuze 2004:4-5, 83, 87-89, 157, 205, 261, 339). ${ }^{17}$ I hereby propose that this final image of the antipodal utterance to be characterized as the dissolved sign of postmodernism.

Deleuze's characterization of this dissolution parallels the realities of death, violence, sacrifice, or dehumanization exemplified in this paper. At the same time that bodies lose their unity and the self its identity, language loses its denoting function, its distinct sort of integrity: not as someone who expresses himself but with respect to something that is purely expressed. Such a Deleuzian paradigm transforms the model of

15. The imagery of emptiness recurs in Kristeva's work on the empty sets or disjunctive additions of carnivalesque language, as she describes "the vacancy of judging consciousness and sign" (1980:79, 142).

16. For a Deleuzian rendition of ambiguity in the conceptual universe of Cuban divination and the current role of a postmodern descriptive language in anthropology, see Holbraad (2012). For a further discussion of Deleuzian anthropology and the concept of disjunctive synthesis or inclusive disjunction, see Viveiros de Castro (2009). To compare with the notion of "internal discontinuities," see Strathern (1991:xxiii).

17. Note the same metaphor of "dissolving the sign" emerged in Kristeva's semanalysis (1980:18). language - being different from a subjectivity expressing itself. An integrity of language seems at odds with the several worlds of a Deleuzian philosophy. Deleuze shatters the boundaries of our contemporary metalanguage by postulating an experimental personal pronoun, the fourth person singular (with every signification suspended), for a description of the dissolved self, lost identity, and copresence of sense and nonsense (Deleuze $2004: 133,159-160,338)$. It is notable that it is indeed a pronoun or pronominal expression that manages to capture Deleuze's malaise.

This fifth image also needs to take into account the wider postmodern cosmology or ironic condition surrounding these theories of the sign. Lambek notes irony is a recognition of the inherent incompleteness of any particular form of knowledge and denotes perspectivism. Irony is a dimension of selfunderstanding, as one is cognizant of the limitations of one's own perspective. Irony stands for the uncertainty of holding things in a double vision, or not to speak with an assurance one does not have. It is not necessarily an intentional discursive strategy but is embedded within particular cultural genres. Irony may be cynical, humorous, or detached, but often it is something deeply felt, some inner recognition about the contingency of truth. As such, irony is highlighted in the religions of many non-Western societies (Lambek 2004:3, 5, 7-8, 11, 16). Burke understood irony as a consideration of the standpoint of the participation of all the terms rather then from the standpoint of any one participant (Burke 1945:513). A further comparison with Burke's notion of "true irony" is apposite. True irony does not denote a superiority to the enemy but is based upon a sense of fundamental kinship with the enemyas one needs him, is indebted to him, is not merely outside him as an observer-but contains him within. True irony denotes being consubstantial with the enemy (Burke 1945:513-514). Lambek, however, alerts us to a possible important distinction and the specificity of a postmodern cosmology. He argues that, on the contrary, postmodern irony has served as a form of conceit, of knowing both sides, and denotes a sense of superiority to the enemy (Lambek 2004:12).

A critical consideration of ironic modes is particularly relevant for contemporary anthropologists, both in terms of their own cosmology and the realities encountered in the field. Fernandez and Huber consider the ambivalent self as a key feature of the postcolonial condition (Fernandez and Huber 2001:29) and reiterate Brown's call for an ironic ethnography (Brown 1999). This kind of ethnography recognizes the indeterminacy and contingency of the experience of the people constructed as marginal by expansive states - their shifts in allegiance and the ambiguity of their past and present (2001:25). Marcus argues our times are especially prone to irony (Marcus 2001). This ironic predicament is enhanced by globalization or the reach of nonlocal agencies into the local, so that conventional ideas of the social no longer have authority (Marcus 2001:211). This recalls Kristeva's focus on challenges to the social framework and times of abrupt changes in society as well as Renou's attention to volatile political circumstances. I therefore recognize that 
a theory of the sign in these circumstances may well be understood more swiftly on the basis of a postmodern cosmology. However, it may help to pay attention to each image of the antipodal utterance I sketched - each belonging to a differing world and analysis - to distinguish them from all too familiar postmodern forms of irony, or a superiority to the enemy.

\section{Concluding Remarks}

I defined the antipodal utterance as a sign that encompasses a radical opposition of meaning and perspective. Such a vocabulary appears to evoke a Bakhtinian notion of "freedom of language" (Kristeva 1980). This concerns speech freed from historical constraints, when the word has no fear of incriminating itself and is free from presupposed values - "without distinguishing between virtue and vice." Kristeva remarks that "it has been impossible for classicism or any other authoritarian society to express itself" in this type of language (Kristeva 1980:82-83). ${ }^{18}$ However, this is not just about a mere celebration of irony and perspectivism. We need to consider an inevitable and context-specific balance between perspectivism and a working stability of language and meaning (Lambek 2004:16). Note that, within Amerindian perspectivism, the experience of simultaneity of perspectives only occurs in shamanic performance - only shamans are capable of transiting the various perspectives (Viveiros de Castro 1998:483). In work by Devisch, it is ritual devices that cultivate a simultaneity of opposites for the afflicted (Devisch 1993). However, the texts by Renou and Malamoud on ancient India enable us to consider the possibility of a more pervasive use of antipodal utterances.

This paper indeed concerns only linguistic techniques and the antipodal word. It is, however, of interest to note Severi's analysis of visual paradox and the ritual image. In situations of intense conflict, the anthropological concept of syncretism appears to be incomplete and overhasty. A paradoxical figure emerged among the Apache: a figure doubly defined as not only Christ on the cross but also Lightning and Snake - the image of a crucified snake. Severi concludes that the memories of an extremely violent conflict engender not just a cultural hybrid, a mixture of cultural traditions, "but, well and truly, a paradox." Among European Christians involved in the conquest, he discerns a similar process: "Lady Sebastiana, like the Apache Christ, embodies and at the same time confronts her enemy." Images on both sides become transformed (Severi 2015: 22-23, 268, 273, 279, 288, 325, 333-334).

Severi makes use of the term "complex images" to describe images that take a form that is not linear but is based on simultaneity and a condensation of contradictory elements. Here I pay attention to the "indispensable vocabulary" mobi-

18. This is a verbatim quote from Kristeva (1980:83), which I interpret here as a comment on language ideology within authoritarian societies, with particular reference to classicism and the novel in postmedieval Europe. lized by Severi with which to decipher the memories of conflict, which include paradox (Severi 2015:23, 313, 317, 324, 332). I notice a synergy between this visual anthropology and the vocabularies I quoted when depicting images of the antipodal word. Chimera - a reference to the monstrous hybrid creatures of Greek mythology-lends itself well for a visual anthropology of "intense images of unresolved conflict" (Severi 2015:318). I opted for the term "antipodal" to accentuate the emptiness and inherent tension of verbal paradox.

Viveiros de Castro's call for a perspectivist theory of the sign leads me to a consideration of Kristeva's notion of the sign as matrix (1980:146). An antipodal matrix differs from the image of the word implied within the concept of indexicality, or a focal point from which multiple contextual meanings emanate. Kristeva addressed the presuppositions of our metalanguage, which are not necessarily productive (1980:88). Antipodal utterances are not necessarily amenable to an analysis on the basis of the notion of indexicality. Subjectivism and indexicality appear as two sides of the same coin. A perspective induced by a subjectivity lies at the basis of indexical meaning (Benveniste 1966:227). ${ }^{19}$

Hanks considers the classical definition of indexicality and the variety of things the term is applied to. For Peirce, an indexical sign stands in a relation of "dynamical coexistence" with its object. In other words, the indexical and what it stands for are, in a sense, copresent in the context of the utterance. Hanks argues that the concept of contiguity on which indexicality is based must be defined relative to local standards of copresence and relevance (2001:119-120). The question is whether, in the case of the antipodal utterance, spatiotemporal or contextual contiguity is relevant. Radical semantic rupture, or U-turns in meaning, presuppose simultaneity and tension. The principle of simultaneity characterizing the antipodal utterance appears to be at odds with the sequentiality inherent within a pronominal paradigm, or the sequence of "momentary references" characterizing indexicality (Benveniste 1966: 226). Such words denote a simultaneous awareness or the cognitive existence of opposing contexts, which is not readily captured by the notion of indexicality or the sequentiality of shifting contexts of speech. The simultaneity of the opposing worlds questions the necessity of spatiotemporal contiguity and subverts a core principle of an observational method within linguistic anthropology: indexicality. I would therefore argue that nonmodern metalanguages (or indeed metaritual) may provide a valuable vantage point for an anthropology of language.

Varzi's work on the spatial realities of affluent youth in Northern Tehran draws a comparable analytical image. Living at the crossroads of Chanel scarves and the Islamic republic's images of martyrdom, such youths inhabit a hyperreality char-

19. In Kuechler's work, related topics are addressed through a critique of "anthropological modeling." A conception of space as proceeding from the human body becomes deconstructed. "De-centered spatial cognition," in Kuechler's analysis, appears as a key term to take into account multiple reference systems $(2003: 213,218)$. 
acterized by hypervigilance - the ability to be in two or three different spaces at once, or not at all. She highlights the youth's hyperawareness and capacity to exist in two or more spatiotemporal dimensions simultaneously. The image of the enemy within, or the close-by enemy, emerges. More importantly, Varzi argues that modernist ideological projects and revolutions are unlikely to find success in societies where people have become adept at moving through such hyperrealities (2006:128, 130). This vigilance, highlighted in the work of Varzi (2006) as well as in Viveiros de Castro's analysis of shamanic vision $(2007: 16,19)$, constitutes an entry point to consider the paper's initial quote by Borges. ${ }^{20}$ People may well be "afflicted with unreality" simply by being less vigilant and by not truly paying attention to opposing worlds - "as so many Englishmen are" (Borges 1944:10). ${ }^{21}$ I hereby define the antipodal utterance as the linguistic counterpart of hyperreal gestures and modes-ofbeing based on the simultaneity of opposites. I propose to call this sharp communication, as this not only concerns utterances but also perceptiveness and alertness - vigilance. The latter may well include what Empson called "a birdlike wakefulness; unchanging in irony" (2016:100).

I suggest that this kind of awareness has been addressed by Fabian's term "negativity." Consensus and dialogue appear as "suffocatingly positive," as do identity and authenticity. Negativity or the negation of concepts and beliefs constitutes a deeper challenge. Regarding case material on storytelling in Lubumbashi, Fabian states "we no longer have before us a distinction or separation of two worlds or two kinds of discourses about the world, but a contradiction" (2001:88-91). ${ }^{22}$ After a rereading of Adorno's Negative Dialektik (1966), Fabian eschews the term "dialectical" $(2001: 89,218)$. He prefers to "avoid dealing with contradiction dialectically and dissolve it into harmless difference" (J. Fabian, personal communication). The trivial or mechanistic meanings of "dialectics" - and its stultifying mathematics that turns the negation of a negation into positivity - are disavowed. Other keywords appear on the scene, such as cultural self-suspicion (or the split of a culture into itself and its suspicion of itself), the notions of survival and the history of negation, self-mockery, incongruity, and the performative work of negation - parody and irony. Negativity is

20. Bear in mind a key aspect of Viveiros de Castro's ethnography of Amerindian perspectivism or "the capacity to see oneself as the enemy" (1992:249).

21. Kohn addresses a similar idea articulated by the Runa in Ecuador's Upper Amazon as he coins the term "cosmological autism." The challenge for the Runa is to avoid the state of monadic isolation by which they lose the ability to be aware of other selves that inhabit the cosmos. Cosmological autism stands for a lack of awareness or the loss of the ability to recognize other perspectives, and Kohn includes a valuable list of examples (2007:12, 20).

22. The example cited here does not concern a single antipodal word but is a stock phrase and opening line of stories told in Swahili. The opposing terms hadisi (truth from hadith) and bongo (lie) are juxtaposed in a proverbial expression that Fabian retranslates as "story appears, lie appears": a contradiction between truth and lie (2001:91, 218). defined here as a "dis"-position or "habit of distrust in positing, and in the positivity that goes with taking positions" (2001:89$90,93-94,97,99,100)$. In my understanding, the quote taken from Malamoud's work (1996) and title of this paper - a space that will never be filled - can accentuate such a performative and communicative stance. Fabian's negativity or distrust of occupying a position appears linked to an awareness and performance of undissolved contradiction - not fettered by dialectical ties.

This paper is made of a superposition of supplementary images of this kind of awareness and the sharp communication that goes along with it (see table 2 for an overview). The assemblage of concordant images, each with a different starting point, disciplinary remit, and vocabulary, conceived together, entails a common conceptual thrust. This framework is cumulative rather than exclusive, and the set of selected examples is indeed arbitrary. Besides, each image needs to be differentiated and specified against the background of a pervasive postmodern mode of thought. This exercise involves a deconstructive linguistics but also a recognition of the limits of an anthropology of linguistic phenomena as observable practice. Antipodal utterances take on a key role for a delineation of the "limits of a phenomenological linguistics" (Kristeva 1980:143). Postmodern culture, however, does not necessarily provide a privileged vantage point or language of analysis. The metalanguage of a modern linguistic anthropology, the well-oiled paradigms of a literary criticism of the ironic, and Deleuzian anthropologies at once support and subvert a possible analysis. Linguistic techniques utilized to address incommensurable worlds - predation, risk, violence, sacrifice, revolution - are likely to transcend representation by a modern metalanguage and a postmodern understanding of irony.

Each image I depicted addresses a supplementary reality: manioc beer for the Araweté, the notion of nawa in the Pano languages of Amazonia, fula for the Yaka, the Sanskrit notion of footstep and substantive, the seventh type of ambiguity for the English, Nietzsche's brutal realities, Burke's true irony, or a postmodern emptiness and perpetual motion. They can be scrutinized in terms of being an essential anchor for a study of sharp communication. This decentered analytical framework features a range of independent concepts that point in a similar direction: Viveiros De Castro's shamanic experience of perspectivism, Renou's ambiguity of the referent, Detienne's intermediate zone, Malamoud's suspended betweenness, Devisch's Janusian thought, Burke's consubstantiality in true irony, Kristeva's logic of nonexclusive opposition, or a Deleuzian continuously displaced subjectivity. Sharp communication is but a term; a nexus to justify the superposition of the five images I chose.

Some of the images are difficult to classify as religious or secular, Eastern or Western. Renou's oeuvre confounds our notions of grammar, metalanguage, and religion. Meanwhile, the intellectual trajectories of both William Empson and Julia Kristeva point eastward. Kristeva's pioneering work in the late sixties went hand in hand with the sinology of Joseph Needham, 
Table 2. Overview of the five images

\begin{tabular}{|c|c|c|c|}
\hline Image & Context & Linguistic description & Key reference points \\
\hline 1. Contemporary hunter-gatherers & $\begin{array}{l}\text { Perspectivism (including } \\
\text { Amerindian thought) }\end{array}$ & $\begin{array}{l}\text { The empty sign, pronominal forms } \\
\text { of representation }\end{array}$ & $\begin{array}{l}\text { Hunting ideology, predator-prey } \\
\text { relationship }\end{array}$ \\
\hline 2. Rigveda, ancient India & Vedic thought & $\begin{array}{l}\text { U-turn in meaning, word as } \\
\text { "footstep," a space that will } \\
\text { never be filled }\end{array}$ & Political flux and uncertainty \\
\hline 3. Yaka cosmology, Central Africa & Sacrificial ideology & $\begin{array}{l}\text { U-turn in meaning, sacrificial } \\
\text { substance and substantive, } \\
\text { reality not yet appropriated by } \\
\text { an author, or perspective }\end{array}$ & $\begin{array}{l}\text { Double-bind experience of } \\
\text { tradition versus survival }\end{array}$ \\
\hline 4. Four centuries of English poetry & $\begin{array}{l}\text { Literary weapon among } \\
\text { the English }\end{array}$ & $\begin{array}{l}\text { The "blank cheque of paradox," } \\
\text { a seventh type of ambiguity, } \\
\text { relational opposites }\end{array}$ & $\begin{array}{l}\text { Narrow border of experience } \\
\text { between incommensurable } \\
\text { worlds }\end{array}$ \\
\hline 5. Contemporary French philosophy & Postmodern cosmology & $\begin{array}{l}\text { The dissolved sign, the logic } \\
\text { of nonexclusive opposition, } \\
\text { emptiness; an anonymity, } \\
\text { a blank space }\end{array}$ & Death, birth, sex, and revolution \\
\hline
\end{tabular}

a close friend at Cambridge. ${ }^{23}$ Kristeva became immersed in Needham's Science and Civilisation in China (1954), a bridge of monumental proportions between the cultural history of China and the West. Kristeva learned Chinese and visited China with the Tel Quel group (see Kristeva 1977). This intellectual undercurrent has perhaps been overshadowed by the role Kristeva played in Roland Barthes's seminar, her reading of Bakhtin and coinage of intertextuality, or more generally the development of poststructuralist thought in France. Empson's Structure of Complex Words was published in 1951 after spending formative years in Tokyo (1931-1934) and Beijing (1937-1939, 19471953). ${ }^{24}$ The synopsis of images 4 and 5 in table 2 should be read while keeping these personal pathways in mind (also see note 5 as well as this paper's references to Bachnik's work $[1982,1986$, 1994]).

The handshake and gesture of a survivor of torture that I depicted at the beginning of this paper allude to the possible wider relevance of a study of the simultaneity of opposites. The tension of being and being seen "like a wolf" or a man, being addressed as predator or human, constitutes the antipodal nature of this encounter. The "region or moment of indiscernibility between the human and nonhuman" is evoked. ${ }^{25}$ This paper concerns the blurred boundary between humanity and the world of animals and enemies, more specifically the linguistic manifestations of this gray zone. ${ }^{26} \mathrm{~A}$ struggle for survival regardless of human traditions, the brutality of war, pre-

23. Kristeva, personal communication, meeting of the Kristeva Circle, Stockholm, Sweden, October 13-16, 2016.

24. Notable is the brief reference to the Taoist word, as Empson argues one should always try to interpret paradoxes and recognize contradiction (1951:53).

25. An expression I borrow from Viveiros de Castro (2007:15).

26. For my earlier research within this field or a linguistic anthropology of extreme violence, see Argenti-Pillen (2003) and Pillen (2015) as well as a recent discussion of language and the translation of experiences we have dubbed "traumatic" (Pillen 2016). dation of fellow humans, and sexual desire become sedimented into antipodal utterances. The relative objectivity of our ethnographic endeavor inherent in its metalinguistic props leads to the portrayal of cultures in which perspectivist or ironic stances and their potential may be underrepresented. Fernandez and Huber regard ideological overcommitment and overconfidence - or all the arrogant self-satisfactions characteristic of partisanship - as the source of much adversity. Meanwhile, fallibilism and a sense of human frailty induced by irony are to be valued as a particularly effective kind of politics, or rather antipolitics (Fernandez and Huber 2001:17). Antipodal utterances bring incommensurable worlds into sharp cognitive relief and make them susceptible to consciousness and accurate consideration. I therefore do not loose sight of the political dimension of this debate, epitomized in the work of Renou as he translates: "May the law protect me against the law" (1939: 231). It is a tolerance for this kind of multiplicity, which for us - still modern subjects - might indeed be enigmatic.

Irony, alone, piercing through the linguist's metalanguage, is the timid witness to this drama. (Kristeva 1980:27)

\section{Acknowledgments}

Earlier drafts of this paper were presented at the Culture, Identity and Language Seminar, Institute of Education, University of London (2005); the conference of the American Anthropological Association, Washington, DC (2005); in the panel Language Weapons: Representations and Linguistic Repercussions of Violence, the Writing War Seminar, Department of History, Queen Mary University (2006); the Hull Theory Network Workshop Series on Totalities, Terror, and Dangerous Emotions, University of Hull (2007); and the Medical Anthropology Research Seminar, University of Oxford (2015). I thank Jan Blommaert, Charles Briggs, Shonna Trinch, Catherine Merridale, Mark Johnson, and David Parkin for the invitations and comments. The argument was further de- 
veloped through an interdisciplinary dialogue at a conference on Ritual Dynamics and the Science of Ritual, University of Heidelberg (2008). I also acknowledge Martin Holbraad for reading a draft and exchanges when co-teaching a course titled "Voice and Memory-Humanism and Alterity" (2005-2007). Since 2009, the contents of this paper have constituted a module in my course in linguistic anthropology, and I am grateful for the many cohorts of students who have helped me to think this through. I would like to thank Don Brenneis for his support as well as discussion of references and Eduardo Viveiros de Castro for his interest in this paper's destiny. I am also indebted to comments by Johannes Fabian, Charles Stewart, Rebecca Empson, Stephen Colvin, and Giulia Cavicchioli. All mistakes are, of course, mine. This work articulates itself within the context of the Anthropology and Language Committee of the Royal Anthropological Institute in the United Kingdom as well as a research framework at the interface of anthropology and the humanities: the Quotation Lab at University College London. I have conducted field work in war-torn Sri Lanka (19961998) and among Kurdish refugees in London (2004 to present) and would like to thank everybody who participated in these studies for their patience and insights. Research was funded by the Leverhulme Trust, Nuffield Foundation, and grants from the Harry Frank Guggenheim Foundation for the Study of Violence, Aggression and Dominance. A mid-career fellowship of the British Academy (2016-2017) allowed me to finalize the paper. Finally, I thank the editors, reviewers, and commentators for their critical support.

\section{Comments}

\section{Rebecca Empson}

Department of Anthropology, University College London, 14 Taviton Street, London WC1H 0BW, United Kingdom (r.empson@ucl.ac.uk). 2 III 17

In A Space That Will Never Be Filled, Dr. Pillen puts forward a compelling case for a term that refers to the simultaneous manifestation of opposing worlds and utterances - antipodal. Antipodal encompasses a radical opposition of meaning and perspective. As an introduction to its manifestation, we are treated to a rather terrifying fieldnote, recounted originally in Kurdish, of how Lorîn's husband met his torturer unexpectedly while thinking he was going to redecorate a flat. Dr. Pillen explores the antithetical worlds encapsulated in this moment when the men, who were once "wolves," or enemies to each other, are unexpectedly reunited as humans (albeit trembling ones). This provides the starting point for a "crossdisciplinary search for the linguistic counterparts to this kind of gesture," where words "contain their opposite and embody a U-turn in meaning." The antipodal utterance is thus explored through five distinct case studies, or images.
The first image takes us to the Amazon and an animist society where a drink may be understood as manioc beer or blood, depending on whether you inhabit the world of humans or jaguars. Only shamans can "see" both properties at once, with their ability to transcend worlds and take on different forms. Defining "manioc beer as an antipodal utterance," we learn of its simultaneous meaning, only held in place when worlds are ontologically fixed. In the second image, we learn, through Renou's study of the metalanguage of Sanskrit, how this is a "device to study antipodal utterances." Here, an "enigmatic word might draw its strength from the tension of the question to which it gives rise or the space opened up by this question." In the third image, we learn of the prevalence of the simultaneity of opposites during sacrifice and divination.

At this image, my mind is drawn to the opening fieldnote. Can one inhabit the two worlds simultaneously - the wolf and the human? Is a trembling hand the slow possible manifestation of its opposite? Certainly, from the opening example, one can imagine a tension existing between two worlds on the brink of colliding, but this does not seem to be the same as the possibility of the shaman's position in the Amazon, being able to see both beer and blood. The men in the opening example do not turn into wolves; they remain trembling humans to each other, fixed in their positions, even if the possibility of a U-turn exists as a potential.

By the time we get to the fourth image, we learn of the "border of experience that two incommensurable worlds hold in common" in English poetry. The poets argue for "a narrow thing within one word," not something between worlds, and so, again, the suspension of opposites appears to be the line in between the two, rather than their simultaneity, something vastly different from the world of the jaguar and the world of the human. One wonders how lines of comparison are being drawn, but the tension is sustained.

In the fifth image, we learn how postmodern cosmology allows for opposing frameworks, or logics, to be maintained as they exist in parallel, drawing the subject in multiple directions, something characteristic of "the dissolved sign of postmodernism." This final point reminds me somewhat of Foucault's (1986 [1967]) description of the paradoxical power of the mirror. On the one hand, the mirror is a kind of utopia; it opens up a virtual space below the surface, giving "my own visibility to myself." (24). On the other hand, it is also a kind of heterotopia. "From the standpoint of the mirror I discover my absence from the place where I am since I see myself over there" (24), and in order to do so, I have to pass through a virtual point. This visual paradox, and the fine line it instantiates between two images, brings to mind the idea of figure-ground reversals and the contour between two images or senses, which is sometimes held in place and sometimes quivers and shatters.

In my own work on the role of mirrors in Mongolian households that reveal two perspectives simultaneously (Empson 2011), I have examined the Rubin vase-profile illusion. Developed in 1915 by the psychologist Edgar Rubin, the vase- 
profile illusion is an image in which we either see two black profiles facing each other in front of a white background or a white vase on a black background. Rubin developed this image to illustrate the dynamic nature of subtle perceptual processes. Because one of the contours of the image is shared with the other, it is difficult to perceive both images simultaneously. Instead, our vision fluctuates between the vase and the profiles. As one image becomes the background, the other becomes the foreground and vice versa. The ability to see one image and then the other, but not the two simultaneously, is referred to as "contour rivalry" (i.e., we shift attention between the shape and the contour). The reversal of images that the observer perceives in the vase-profile illusion is due to their individual tendency toward biasing either the shapes or contours, making one interpretation stronger than the other (Arnheim 2002 [1954]: 223). Only, perhaps, the Amazonian shaman, or the postmodern subject, or even the Mongolian visitor who sees themselves in the mirror at the household chest, can see the two perspectives simultaneously. Momentarily, opposites are held in place so that, flickering into view, a new image emerges sharply. What is the context that allows for such a moment? Is it a word, the mobilization of a term, or a constellation of other things?

Right before the conclusion, Dr. Pillen states that it "may help to pay attention to each image of the antipodal utterance I sketched - each belonging to a differing world and analysis." This point seems crucial. Instead of being asked to hold them simultaneously - that they are somehow connected-we are invited to imagine that each image belongs to a different world. In essence, the five images point to "concepts which point in a similar direction" but are not exclusive or inclusive of each other. Simultaneously connected, but also not connected at all. Bringing incommensurable worlds into relief and into our consideration momentarily does have an effect, and it is certainly an enigmatic juxtaposition (montage?). I am just not sure how much they can be compared at all. In fact, it seems to me that Dr. Pillen has the idea that these meanings should be kept in tension through the five examples, pointing to the parallel movement of meaning in antipodal words themselves and their resistance to being held in any single place.

Instead of more images, it would be good to have more examples of sharp communication, to discern their actual sharpness in action - that is, to perceive the realization of opposing meanings as they unfurl. In Mongolian, where words have effects on worlds, much like actions shooting from the mouth, this appears when someone praises a third person. Sometimes with this praise comes the gradual realization that this utterance is, in fact, its opposite (i.e., malicious slander or a curse). Too much praise invites its polar opposite. The tension between granting good wishes and instantiating their tipping point, black curse words, is never exactly clear. Depending on context, they may have opposite or simultaneous meanings and effects. Sharp communication such as this is known as "White Black Tongue Mouth" (tsagaan khar hel am). To hear more about the antipodal utterance's effects in action, such as the movement of meaning of sharp words, would highlight the tension that is kept in place as meanings are deferred or shift and allow us to observe the power such words have on altering the worlds in which they are uttered.

\section{Guilherme Orlandini Heurich}

British Academy Newton International Fellow, University College London, 14 Taviton Street, London WC1H 0BW, United Kingdom (guiheurich@gmail.com). 13 III 17

Alexandra Pillen's call for a redescription of the sign echoes Viveiros de Castro's (1998b) own in relation to Amerindian metaphysics, and her paper provides us with the material to understand what this new semiotic theory would not befocused on neither substance nor subject, neither property nor authorship, and neither sequential nor consecutive-but leaves us intrigued to know what it would look like and where we might go from here. Two central aspects of her paper contribute to a new theory of sign, her critique of the subject and the simultaneity of utterances, and the anthropology of languagewith its tendency to become lost in indexical forests - could certainly benefit from Pillen's displacement of substance and restriction of continuity. However, new semiotic theories have emerged and then drowned during the last hundred years, so there is always a chance that a new contender will simply slip into old theoretical shoes. To suggest how this might be avoided, I will address one of the most important figures in this line of research, Ferdinand de Saussure, through recent philosophical reinterpretations of his work, in order to highlight those aspects of Pillen's paper that could provide a path for an alternative theory of the sign.

Perhaps one of the most enduring ideas about the sign is that its meaning derives from the system in which it is placed (i.e., from its relation to other signs), and it would seem that Saussure put forward two ways to interpret this. On the one hand, we can say that a sign's identity is defined by it not being what other signs are, that a sign goes through a process of identification that stabilizes its meaning by means of opposition to other signs. A sign is what other signs are not, and it thus becomes a stable entity. However, a second possibility emerges in which the sign is defined by the intrinsic possibility of not being what it is, which is how I understand Patrice Maniglier's recent $(2005,2006,2007)$ reinterpretation of Saussure. The chance that a sign could have meant something else is always lurking somewhere in its meaning, and this possibility can never be erased, since it defines the sign as something that could be something else. This does not mean that the sign could have been something else or that it will be something different, but it stresses that an Other is within the sign, here and now. In this second understanding, identification is only partial, and the sign is never completely stabilized.

Maniglier also claims that Saussure puts forward a completely new syntactic theory, one which "is not the result of a subject's activity" and "is not based on the relationship be- 
tween form and content, but that between a specific content and other possible contents" (Maniglier 2005:44). If we follow Maniglier's take on Saussure, this second approach allows us to move away from notions such as substance, because "[w]hen Sausurre states that the sign is a 'double entity' he does not mean that it is anything like a double substance, but rather that it is not substantial" (Maniglier 2006:276).

Both Maniglier's discussion of the ontology of Ferdinand de Saussure's theory of the sign and Alexandra Pillen's images of the simultaneity of opposites lead us to rethink what substance means. When she discusses Bachnik's (1982) work, for example, Pillen acknowledges the influence of theatre and drama in the definition of pronouns. This paradigm, in which actors dialogue as authors and interlocutors, does not fit well with the images presented by Pillen. Finding a new semantic landscape for people who converse through oppositional words thus requires a shift from analysis focused on the subjects as actors and authors to a perspective in which meaning is tense, ambiguous, and ironic. We might add the idea that a sign is open to the Other to this critique of the subject and the simultaneity of utterances: an Other who is not a subject, actor, or author, but who might be oppositional, contrasting, and antipodal. Pillen's analysis would thus allow us to reconcile the sign's metaphysical aspect with an ethnographic description of symbolic modes of existence that challenge Western conceptions. This would be a very important step-however small it might seem - toward a redefinition of the sign.

\section{Miglena Nikolchina}

Department for Theory and History of Literature, University of Sofia, 15 Tsar Osvoboditel Boulevard, 1504 Sofia, Bulgaria (nikolchina@gmail.com).6 III 17

Alfred North Whitehead, famously, makes the observation that the European philosophical tradition "consists of a series of footnotes to Plato" (1978:39). Less sweepingly, Jean-Luc Nancy remarks that "every great study of Hegel is, in effect, a study of the Aufhebung" (1973:18, n. 4). Today, after Alex Pillen's colorful anthropological study presented here, one might be tempted to add that, in the last century or so, not only European philosophy but a host of other theoretical fields have provided, knowingly or not, a series of footnotes to Hegel's Aufhebung, this notorious term signifying, on the one hand, annulment, destruction, and cancellation and, on the other, preservation and conservation. In his reflections on the term, Hegel turns the capacity of this word to embrace two opposite sets of meanings into an example of the unique philosophical advantages and "speculative spirit" of the German language. ${ }^{27}$ As Derrida notes in his own "sharp communications" (as we could put it after Pillen) with the German philosopher, ac-

27. For a discussion of this, see Carlson (2007:30, nn. 71-72). cording to Hegel, Aufhebung is "the speculative concept par excellence [. . .], the concept whose untranslatable privilege is wielded by the German language" (1978:257).

Alex Pillen's reference to Hegel appears comparatively late in her text. Pillen's striking account of "antipodal utterances" juxtaposes languages, rituals, gestures, and images and encompasses examples from manioc beer to postmodern emptiness and perpetual motion. It brings together Viveiros De Castro, Renou, Detienne, Malamoud, Devisch, Burke, Kristeva, Deleuze, and more. Against this vibrant and, as she herself notes, cumulative background, Hegel is introduced by Pillen through Fabian's critique of Hegelian dialectic, a critique that has been a shared antipodal ground for various thinkers from Marx to Adorno to Derrida and after. However, the antipodal term itself, Aufhebung, is never mentioned by Pillen. Nor is the other most debated German concept, Freud's das Unheimliche, this uncanny word that negates and confirms the two opposing meanings of its antonym, das Heimliche, with both antonyms designating simultaneously what is familiar and agreeable and what is concealed and kept out of sight (Royle 2003).

Yet it is against this hidden philosophical and psychoanalytic tradition that the full scope of Pillen's unheimlich findings, so disquieting with their defamiliarized familiarity, might come into relief. To begin with, there goes the speculative uniqueness of the German language. Pillen's survey with its wide geographical, historical, and discursive range demonstrates that the propensity for "words that contain their opposite and embody a U-turn in meaning" does not belong to the untranslatable privilege of a certain philosophically inclined language but is, indeed, pretty common in various circumstances where the "struggle for survival regardless of human traditions, the brutality of war, predation of fellow humans, and sexual desire become sedimented into antipodal utterances."

An important outcome of this wide-ranging exploration is the juxtaposition of premodern and modern (and postmodern) capacities to "address incommensurable worlds - predation, risk, violence, sacrifice, revolution.” In Pillen's analysis, this juxtaposition works in favor of the premodern, which appears to be more at home (more heimlich, antipodally speaking) with incommensurable worlds, with gray zones, with the blurred boundary between humanity and the world of animals and enemies, and so on, while "the metalanguage of a modern linguistic anthropology, the well-oiled paradigms of a literary criticism of the ironic, and Deleuzian anthropologies" somehow fall short of this task. One of Pillen's illustrations of being inhabited by the enemy, which antipodal utterances involve, is Varzi's study of northern Tehran's youth and their capacity to live at the crossroads of Chanel scarves and the Islamic republic's images of martyrdom, in a "hyperreality," characterized by "hypervigilance" - the ability to "exist in two or more spatiotemporal dimensions simultaneously." Pillen marks as even more important Varzi's argument that "modernist ideological projects and revolutions are unlikely to find success in societies where people have become adept at moving through such hyperrealities." 
It is at this juncture that Pillen resorts to Fabian's critique of Hegelian dialectic as dissolving into "harmless difference." Now, few concepts have proved to be less harmless than Hegel's Aufhebung. While it was criticized, downplayed, and reconceptualized in the vein indicated by Pillen's study, which led her to dismiss it, there was also the Russian case, where the Aufhebung was enthusiastically acted out in the Bolshevik Revolution as the epitome of preservation through destruction. There was, hence, a curious movement in opposite directions, which became implemented in the reverse translations of Hegel's term as an either upward or downward vector. We might say that the U-turn the Aufhebung took to the west of Germany was ironic and to the east revolutionary; in both cases, however, it became complicit with profound changes (Nikolchina 2013). We may like it or not, but its formidable and hardly reassuring potential to articulate violence and revolution has had its historical heyday and has again resurfaced theoretically, as in, for example, Catherine Malabou's transformation of the Aufhebung into "plasticity" qua simultaneously "sculpture" and "explosion" (Malabou 2005).

So here goes my query. Pillen aligns Fabian's understanding of negativity with the premodern take on antipodal utterances as better suited to provide an adequate perspective on phenomena like the multidimensional hypervigilance of Northern Tehran's youth. As a critique of the not sufficiently watchful descriptive capacities of modern metalanguages and "well-oiled" paradigms to address sharp communications, she does make a powerful point. My own observations on the neutralization of contradictory meanings in the post-Cold War situation could both provide yet another example and benefit from Pillen's insights (Nikolchina 2014). The question nevertheless remains whether a sheer awareness of the "cognitive existence of opposing contexts" would not amount to, precisely, "harmless difference." Varzi's observations on the adeptness of smooth movement through contradictory realities seem to imply so. To put it differently, while Hegel's dialectic, rather than being harmless, can raise concerns about plasticity qua explosion, Pillen's approach to antipodal utterances through the freezing of undissolved contradiction strikes me as risking the perpetuation of the handshake with the torturer of which she tells at the beginning of her study.

\section{David Parkin}

Emeritus Professor of Social Anthropology, University of Oxford, Oxford, United Kingdom (david.parkin@anthro.ox.ac.uk). 15 II 17

We are presented with a poignant example of how verbal labeling can dehumanize and/or rehumanize. A group violates an individual who, much later, treats respectfully one of the original perpetrators. Caught alone and without the savagery of his group, the perpetrator trembles with fear and/or humiliation. The case reveals the two meanings of the bully as aggressive (pack wolf) and cowardly (lone wolf). The formerly violent becomes the fearful later, reversing the meaning of his individuality and of that of the victim. This is the contrastive concept of human individual both for and against humanity, yet also inextricably part of it. The argument is thus set, not within socially dissociated linguistic or grammatical contours, but within social process. This social process is fundamental to the semantic shift. It invites us to consider "antipodal" words as cognitive and emotional responses to social dilemmas and destruction. The antipodal word is seen not as made up of docile opposites such as a euphemism but of fiercely contrasting meanings in sharp tension. The subject matter is not mundane but is the blood and guts of ambivalent violence, sexuality, and desire.

The article elaborates on this provocative social determination and responsiveness. It addresses "utterances that encapsulate their opposite and effectuate a U-turn in meaning." As far as I understand the argument, this is done by focusing on three features in this semantic shift: recognizing that opposite meanings can simultaneously belong within the same word, that the shift from one meaning to the other involves a communicative rupture, but that there is nothing that marks the actual transition - which is, to that extent, a necessarily unmarked space "which cannot be filled," for it is precisely its emptiness or nonspecificity that allows opposite meanings to be part of the same word and yet to stand apart from each other.

There is thus a dynamic in antipodal utterances that draws on several components expressed in five images: ontological categories that enable the perception of different kinds of being to be substituted for each other within the word; polar shifts of meaning via intermediary meanings; the simultaneous play of substantives which, like sacrificial objects, are semantically given as the opposite of each other; seven ambiguities (after Empson) that together allow for semantic opposites to be expressed; and, conversely, the postmodern role of irony rather than substantives to convey semantic opposition.

The five images are very instructive, but I find myself wanting to privilege one in particular as being fundamental and the others as supportive. This is the image of the simultaneity of opposites, which I wish to return to its pairing with sequentiality, using an example of divination. The simultaneity of opposites is the semantic matrix that generates the sequential nature of utterances, in which the oppositions become disentangled and straightened out. Thus, the diviner speaks at first in shockingly contradictory terms, as if hedging her bets on the outcome of her divination. She eventually settles on a consistent line of explanation and no longer juxtaposes opposite meanings. She has moved from semantic simultaneity to sequentiality. But what is this process and how are the other images incorporated in it?

The semantic simultaneity can here be thought of as different niches (ontological, substantive, ironic, pronominal, and so on) into which the diviner speaks, setting up, for example, animality and humanity as polar opposites. This is not to say that she is therefore without speaker subjectivity and intention. It is that, when it is the diviner's obligatory turn within the 
speaking round to say something, she may not be aware of what that something will be beyond the initial cue that she is given. Her speaker subjectivity is thus a permitted, short-term expressiveness that is then taken up by the thematic niches making up the circle of speakers and objects that can be talked about. This simultaneity of possible talk-paths or niches does not preclude choosing which of them to pursue. But in incrementally following up on her initial speaking, she can only choose one at a time.

There is therefore a period of uncertainty between initial speaking and follow-up speaking. The uncertainty rests on the ambiguities of the simultaneity of talk-paths, which may each lead in any number of unanticipated directions. So, initial utterance (proposition one) leads into second utterance (proposition two) via shared and yet unspecified semantic territory. At the core of such semantic resource is the Brenneis concept of indirection. This suits the speech of the diviner who must eventually propose a diagnosis and solution to a presented problem by drawing on such a resource.

Such indirection is effective because it lacks verbal specificity, being indexically made up of allusion and innuendo. To be an effective bridge between initial and subsequent pronouncements, it has to remain that way, (i.e., as a space that cannot be filled with precise denotata). Its cognitive aspect is evident in the author's phrase, "the gap between the beginning of a step and its completion." This is like the gap between at first struggling to master something practical (such as riding a bike) and then knowing it without thinking about it. Struggling ignorance and unconscious competence frame the gap. The antipodal word is something like "to learn" (i.e., failure versus success). It is also the mixed-up language of simultaneity, in which single words can semantically point in opposite directions.

In drawing on the incompleteness of irony and "the blank cheque of paradox," the ambiguities of antipodal utterances are potentially endless. The contrast in meaning making up an antipodal word is only held in place for as long as it reflects social reality (e.g., loyal clansman liable to defect to the enemy and so contrasted as traitor). But social realities do change (mercenary warfare precludes clanship and so dissolves the contrast between clan loyalty and treachery). It is then that speakers may choose from within the simultaneity of meanings a new sequence of, say, cause-effect explanation. This is to suggest a wider processual perspective on the important concept of antipodal utterances.

\section{Reply}

I am tempted to start with the most trenchant comment on the theoretical risk of perpetuating the handshake with a torturer. Prof. Nikolchina evokes undissolved societal contradiction frozen as an antipodal utterance, ceaseless repetition, in the absence of a linguistic escape hatch. Momentary collusion of contradictory worlds here presented as a form of entrapment, a smoothened reality without grip or obvious rift. The dread of such a handshake extends itself to this brief exchange, as she accentuates the definition of the antipodal as resigned anthropology. By contrast, Prof. Nikolchina's oeuvre and consideration of Hegel's term Aufhebung offer a route to uncover the historical potency of a "notorious" antipodal entity. The verb Aufheben comprises a literal gesture of picking something up. As a perspectival sign, the word Aufhebung actualizes a contemplation from below or removal, seen from above as an elevation. Not just a noun, the Aufhebung was acted out in the Bolshevik revolution as "the epitome of preservation through destruction." This illustrates the vagrancy of a theoretical term that has a "formidable potential to articulate violence and revolution." A gesture, German linguistic term, and violent act (Aufheben) coalesce here as a conceptual undercurrent "complicitous with profound changes" to the east of Germany, while surfacing only as irony to its west. "The Bolshevik revolution and its later East European editions" are qualified as "theory turned into terror" and "the demise of a regime by theory" (Nikolchina 2013:13,40). Theory beholden to a remarkably speculative concept-Aufhebung - intrinsically German and above all untranslatable. This was "attributed by Hegel to the proximity between philosophical and everyday language" (Nikolchina 2013:69). This is an allusion to the field of linguistic anthropology, as Prof. Nikolchina opened a distinct door. Had Derrida moved on to read Brenneis (1986) or Parkin (1982), his consternation vis-à-vis Hegel's speculative privilege may have been easier to ride out. This offers a glimpse of anthropology not as "a series of footnotes," predetermined by its relation to Hegelian dialectics and philosophy but as an analytical encompassment of Georg Wilhelm Friedrich Hegel's speech community. Hereby, Aufhebung appears less unique; speculative philosophy and indirection are joined at the hip. There goes Aufhebung's sense of antipodal linguistic privilege; however, its cachet is partially restored by the term's well-documented legacy and the current afterlife that it is given by Malabou (2010).

Prof. Parkin places the anthropology of divination at the center of an understanding of antipodal expression as a social, interactive process. Images from the work of Viveiros de Castro, Renou, or Kristeva depend upon large-scale notions of predation, conquest, or revolution. Prof. Parkin argues that such images support the argument, while only one is fundamental. On the surface, this chosen image concerns divination, but it serves as an entry point to consult ethnographic realities and the precise role of antipodal expression in social interaction. A diviner "speaks at first in shockingly contradictory terms." Speaker subjectivity is defined here as "permitted short-term expressiveness." Societal configurations (such as clan loyalty, treachery, or mercenary warfare) are invoked in this comment, but the emphasis lies on divination itself. Consequently, the contradictions and conflicts of everyday sociality are at stake; illnesses, family strife, poverty, or inequality. 
Prof. Parkin concludes "the contrast in meaning making up an antipodal word is only held in place for as long as it reflects social reality." I would argue that such a processual perspective only emerges from a longue durée approach to linguistic anthropology, spanning decades and generations (e.g., Parkin 2015). The emphasis on divinatory speech opens up a field of enquiry as it represents the diachronic, or a momentary breach into future sociality. Crucially, Prof. Parkin pushes for closer scrutiny of the transition from antipodal simultaneity in divination to sequential discourse - its mechanism - and states that "at the core of such semantic resource is the Brenneis concept of indirection." I propose to refer to "shared territory" (Brenneis 1986) as the salience of this "period of uncertainty" and "yet unspecified semantic territory" is accentuated. Here such a process encompasses a "language of simultaneity in which single words can semantically point in opposite directions." It is an idea I propose to hold onto when turning to other commentators.

Dr. Empson appears to argue that my argument is built upon images that should not be compared with one another. A simultaneity of the opposing worlds of jaguars and humans, as in Amerindian shamanism, being "vastly different" from "the line in between the two" worlds of William Empson's seventh type of ambiguity or an antipodal handshake. How to conceptualize such an Empsonian line? In relation to Foucault's notion of heterotopia and the mirror, an evocative consideration of such a line emerges. The fine line between two images instantiated by the mirror's visual paradox brings to mind the idea of a figure-ground reversal. "The contour between two images or senses, which is sometimes held in place and sometimes quivers or shatters." Dr. Empson asks, "Is a trembling hand the slow possible manifestation of its opposite?" A fine line of oscillation between potential identifications, rather than simultaneity? Would a figure-ground reversal be a more suitable determination of "subtle perceptual processes," which I depicted simply as an awareness of another perspective? Concerning a figureground reversal, Dr. Empson states "because one of the contours of the image is shared with the other, it is difficult to perceive both images simultaneously." Our vision fluctuates between contrasting images. A contour and fine line defined in this manner bring to mind the "narrow border of experience" that two incommensurable worlds hold in common (Empson 1930: 218). Dr. Empson goes on to state that "only perhaps" the Amazonian shaman or postmodern subject can see the two perspectives simultaneously. And then her crucial question"what [. . .] allows for such a moment? Is it the word, the mobilization of a term, or a constellation of other things?"

Foucault's quoted text lists counter-sites that have the "curious property [. . .] to suspect, neutralize, or invert the set of relations that they happen to designate, mirror, or reflect" (1986:24), "certain colonies" being an extreme type of heterotopia, while the ship is heterotopia par excellence (Foucault 1986:27), and the mirror itself being "after all, a utopia since it is a placeless place" (Foucault 1986:24). In a monograph, Prof. Nikolchina addressed the "specific linguistic effect" of heterotopian mirroring or "heterotopian homonymy" and states "heterotopian homonyms are not simply identically sounding words with this or that different meaning-while ostensibly identical, they represent, contest and invert each other" (2013: 47). The familiarity of words and messages conceals their inversion and the contestation that goes together with the mirror effect. An unacknowledged homonymy might not provoke dialogic rearticulation and result in an evacuation of meaning: a desemanticization. Nikolchina discusses this as an unrecognized factor of rhetorical scarcity, "which became apparent during the messy Yugoslav wars and which migrated to other conflicts, as bloody as they are inarticulate" (2013:54). Nikolchina's rendering of Yuri Lotman's semiosphere develops this idea: "a celestial body in semiotic space . . . it can explode and thus open 'semiotic windows' toward the non-semiotic, parts of which it can suck in while casting out its own dead contents back into the nonsemiotizable" (Nikolchina 2013:65-66). Aufhebung as semiotic window toward violence, while some heterotopian homonyms linger as "dead content"? The latter perhaps the spot for a relocation of the grinding point of Johannes Fabian's critique of a Hegelian stance? This is how I propose to reply to Dr. Empson's query about a "constellation of other things," only theoretically for now. Her call for an anthropology of "actual sharpness in action"-invoked here via the Mongolian "White Black Tongue Mouth" — echoes Prof. Parkin's processual approach. In Dr. Empson's words, this is the "realization of opposing meanings as they unfurl."

Dr. Heurich deepens the theoretical dilemma and invokes a semiotic theory that would be "focused on neither substance nor subject, neither property nor authorship, and neither sequential nor consecutive." He turns to Maniglier's tome on the enigmatic life of signs (2006). Here the value of a word emerges as it is engaged in its permanent Saussurean exercises, stretched and negatively defined through differentiation and opposition, leaving a wide margin of indeterminacy (Maniglier 2006:201, 252, 288, 321, 331). Then, I would add, suddenly faced with itself: antipodal. An everyday sign, governed by the principle of indirection but opposing itself, leaves us browbeaten into the domain of the virtual. However, Maniglier argues, "it is not the virtual that turns up to add itself to reality, as if to surround it by a halo" (Maniglier 2006:196). Reality is only authenticated as an actualization of the virtual. This is not using speech to communicate meaning but saying something to be determined later, to articulate a possibility of something to be evoked or actualized, and to say something is nothing else (Maniglier 2006:268). The sign as possibility that "can never be erased," as Dr. Heurich states, is thrown into a domain of evolving differentiation. It is a semantic space that remains unplugged. One might wonder whether this is philosophical pageantry, although this is maybe less so for this journal's serial reader. Knight and Lewis lay out the reversal principle as a key feature to explain the evolution of language (2017). For instance, laughter, an early human signal, is first deployed to display resistance against an external threat. Such aggressive vocal mobbing sounds threatening and ominous 
when aimed at an outsider, but it is reversed when directed inward. Within the group, the rhythmic vocalizations are now relieving and comforting: laughter (Knight and Lewis 2017: 437-438). This compels me to finally return to the antipodal handshake envisaged as a figure-ground reversal - a quivering fine line, in Dr. Empson's terms. Considering the heinous acts committed by such a hand, possibly only a sign of a virtual humanity?

—Alex Pillen

\section{References Cited}

Adorno, Theodor W. 1966. Negative Dialektik. Frankfurt, Germany: Suhrkamp. Ardener, Edwin. 1971. Social anthropology and language. London: Tavistock. Argenti-Pillen, Alex. 2003. Masking terror: how women contain violence in Southern Sri Lanka. Ethnography of Political Violence Series. Philadelphia: Pennsylvania University Press.

- 2007. Mothers and wives of the disappeared in southern Sri Lanka: fragmented geographies of moral discomfort. In Women and the contested state: religion, violence, and agency in South Asia. M. Skidmore and P. Lawrence, eds. Pp. 117-138. Notre Dame, IN: University of Notre Dame Press.

2010. The fear of the sorcerer: finding a peaceful moment for a sacrifice in Southern Sri Lanka. In Ritual dynamics and the science of ritual: state, power, violence. A. Michaels, ed. Pp. 105-131. Wiesbaden, Germany: Harrassowitz.

Arnheim, Rudolf. 2002 [1954]. Art and visual perception: a psychology of the creative eye. 2nd edition. Berkeley: University of California Press. [RE]

Bachnik, Jane M. 1982. Deixis and self/other reference in Japanese discourse. Sociolinguistic Working Paper 99. Washington, DC: National Institute of Education.

. 1986. Time, space, and person in Japanese relationships. JASO Occasional Paper 5:49-75.

-1994. Introduction: Uchi/soto-challenging our conceptualizations of self, social order, and language. In Situated meaning: inside and outside in Japanese self, society, and language. J. M. Bachnik and C. J. Quinn, Jr., eds. Pp. 3-37. Princeton, NJ: Princeton University Press.

Bartholomeus Anglicus. 1535 (1240). De Regionibus et Provinciis (On regions and places), book 15 of De Proprietatibus Rerum (On the properties of things). John Trevisa, trans. London: Bertheleti. Reproduction of the original in the British Library.

Benes, Tuska. 2006. Language and the cognitive subject: Heymann Steinthal (1823-1899) and Friedrich Nietzsche (1844-1900). Language and Communication 26:218-230.

Benveniste, Emile. 1971 (1966). Problems in general linguistics. M. E. Meek, trans. Coral Gables, FL: University of Miami Press.

Borges, Jorge Luis. 2000 (1944). Fictions, the garden of forking paths. A. Hurley, trans. New York: Penguin Classics.

Brenneis, Don. 1986. Shared territory: audience, indirection and meaning Text 6(3):339-347.

1994. Foreword: situated meaning. In Situated meaning: inside and outside in Japanese self, society, and language. J. M. Bachnik and C. J. Quinn, Jr., eds. Pp. ix-xii. Princeton, NJ: Princeton University Press.

Brown, Keith. 1999. Marginal narratives and shifty natives: ironic ethnography as antinationalist discourse. Anthropology Today 15(1):13-16.

Burke, Kenneth. 1969 (1945). A grammar of motives. Berkeley: University of California Press.

. 1974 (1941). The philosophy of literary form. Berkeley: University of California Press.

Carlson, David Gray. 2007. A commentary to Hegel's science of logic. New York: Palgrave Macmillan. [MN]

Deleuze, Gilles. 2004. The logic of sense. M. Lester, trans. London: Continuum.

Derrida, Jacques. 1978. Writing and difference. Alan Bass, trans. Chicago: University of Chicago Press. [MN]

Descola, Philippe. 1986. La nature domestique: symbolisme et praxis dans l'ecologie des Achuar. Paris: Fondation Singer-Polignac et Éditions de la Maison des Sciences de l'Homme.

2013 Beyond nature and culture. Chicago: University of Chicago Press.

Detienne, Marcel. 1996. The masters of truth in archaic Greece. New York: Zone.
Devisch, Renaat. 1993. Weaving the threads of life: the khita gyn-eco-logical healing cult among the Yaka. Chicago: University of Chicago Press. Douglas, Mary. 1966. Purity and danger. London: Routledge.

Empson, Rebecca. 2011. Harnessing fortune: personhood, memory, and place. Oxford: Oxford University Press. [RE]

Empson, William. 1977 (1930). Seven types of ambiguity. London: Chatto \& Windus.

1985 (1951). The structure of complex words. London: Hogarth.

2016. The face of the Buddha. Rupert Arrowsmith, ed. Oxford: Oxford University Press.

Erikson, Philippe. 1996. La griffe des aieux: marquage du corps et demarquage ethnique chez les Matis d'Amazonie. Paris: Peters.

Fabian, Johannes. 2001. Culture with an attitude. In Anthropology with an attitide: critical essays. Pp. 87-100. Stanford: Stanford University Press.

Fernandez, James W., and Mary T. Huber. 2001. The anthropology of irony. In Irony in action: anthropology, practice, and the moral imagination. J. W. Fernandez and M. T. Huber, eds. Pp. 1-37. Chicago: University of Chicago Press.

Foucault, Michel. 1986 [1967]. Of other spaces. Jay Miskowiec, trans. Diacritics 16(1):22-27.

Hanks, William F. 2001. Indexicality. In Key terms in language and culture. A. Duranti, ed. Pp. 119-121. Malden, UK: Blackwell.

Hastings, Adi. 2003. From ritual to grammar: sacrifice, homology, metalanguage. Lanquage and Communication 23:275-285.

Hladik, Murielle. 2008. Traces et fragments dans l'esthetique Japonaise. Wavre, Belgium: Mardaga.

Holbraad, Martin. 2012. Truth in motion: the recursive anthropology of Cuban divination. Chicago: University of Chicago Press.

Howell, Signe. 1984. Society and cosmos: Chewong of peninsular Malaysia. Chicago: University of Chicago Press.

Jamison, Stephanie, and Joel P. Brereton. 2014. The Rigveda: the earliest religious poetry of India. Oxford: Oxford University Press.

Kapferer, Bruce. 1983. A celebration of demons: exorcism and the aesthetics of healing in Sri Lanka. Oxford: Berg.

Knight, Chris, and Jerome Lewis. 2017. Wild voices: mimicry, reversal, and the emergence of language. Current Anthropology 58(4):435-453.

Kohn, Eduardo. 2007. How dogs dream: Amazonian natures and the politics of transspecies engagement. American Ethnologist 34(1):3-24.

- 2013. How forests think: toward an anthropology beyond the human. Berkeley: University of California Press.

Kristeva, Julia. 1975. La traversee des signes. Paris: Editions du Seuil.

. 1977. On Chinese women. London: Boyars.

1980. Desire in language: a semiotic approach to literature and art. New York: Columbia University Press.

Kuechler, Susanne. 2003. Imaging the body politic: the knot in Pacific imagination. L'Homme 165:205-222.

Lambek, Michael. 2004. Introduction. Irony and illness-recognition and refusal. In Illness and irony: on the ambiguity of suffering in culture. M. Lambek and P. Antze, eds. Pp. 1-19. New York: Berghahn.

Levi-Strauss, Claude. 1987 (1950). Introduction to the work of Marcel Mauss. F. Baker, trans. London: Routledge.

Lima, Tania Stolze. 1996. O dois e seu multiplo: reflexoes sobre o perspectivismo em uma cosmologie Tupi. Mana 2(2):21-47.

Lyons, John. 1977. Semantics. Vol. 2. Cambridge: Cambridge University Press. Malabou, Catherine. 2005. La plasticité au soir de l'écriture: dialectique, destruction, déconstruction. Paris: Scheer. [MN]

- 2010. Plasticity at the dusk of writing: dialectic, destruction, deconstruction. New York: Columbia University Press.

Malamoud, Charles. 1996. Cooking the world: ritual and thought in ancient India. Delhi, India: Oxford University Press.

Maniglier, Patrice. 2005. Les choses du langage: de Saussure au structuralisme. Figures de la psychanalyse 2(12):27-44. [GOH]

. 2006. La vie énigmatique des signes: Saussure et la naissance du structuralisme. Paris: Scheer.

- 2007. L'ontologie du négatif. Methodos: savoirs et textes 7. [GOH]

Marcus, George E. 2001. The predicament of irony and the paranoid style in fin-de-siecle rationality. In Irony in action: anthropology, practice, and the moral imaginaton. J. W. Fernandez and M. T. Huber, eds. Pp. 209-223. Chicago: University of Chicago Press.

Mauss, Marcel. 1972 (1950). A general theory of magic. R. Brain, trans. London: Routledge.

Nancy, Jean-Luc. 1973. La remarque spéculative (un bon mot de Hegel). Paris: Galilée. [MN] 
Needham, Joseph. 1996 (1954). Science and civilisation in China. Cambridge: Cambridge University Press.

Nietzsche, Friedrich. 1910. The will to power: books three and four, vol. 15 of The complete works of Friedrich Nietzsche: the first complete and authorized English translation. J. M. Kennedy, trans. Edinburgh, UK: Morrison \& Gibbs.

Nikolchina, Miglena. 2013. Lost unicorns of the Velvet Revolutions: heterotopias of the seminar. New York: Fordham University Press.

- 2014. Inverted forms and heterotopian homonymy: Althusser, $\mathrm{Ma}$ mardashvili, and the problem of 'man.' boundary 2 41(1):79-100. [MN]

Obeyesekere, Gananath. 1984. The cult of the goddess Pattini. Chicago: University of Chicago Press.

Parkin, David. 1982. Straightening the paths from the wilderness: simultaneity and sequencing in divinatory speech. Paiduma 28:71-83.

. 2015. Revisiting: key words, transforming phrases, and cultural concepts. Working Paper in Urban Languages and Literacies. Paper 164. London: King's College London.

Pillen, Alex. 2015. Atrocity and nonsense: the ethnographic study of dehumanization. In Genocide and mass violence: memory, symptom, and recovery. D. E. Hinton and A. L. Hinton, eds. Pp. 342-358. Cambridge: Cambridge University Press.

. 2016. Language, translation, trauma. Annual Review of Anthropology 45:95-111.

Rappaport, Roy. 1968. Pigs for the ancestors. New Haven, CT: Yale University Press

Renou, Louis. 1939. L'Ambiguite du vocabulaire du RigVeda. Journal Asiatique 231(2):161-235.

- 1941-1942. Les connexions entre le rituel et la grammaire en Sanskrit. Journal Asiatique 233(1):105-165.

Robbins, Joel. 2001. Ritual communication and linguistic ideology: a reading and partial reformulation of Rappaport's theory of ritual. Current Anthropology 42(5):591-599.

Roudiez, Leon S. 1980. Introduction. In Desire in language: a semiotic approach to literature and art. Julia Kristeva, ed. Pp. 1-20. New York: Columbia University Press.

Royle, Nicholas. 2003. The uncanny. Manchester, UK: Manchester University Press. [MN]

Schieffelin, Edward. 1987. The sorrow of the lonely and the burning of the dancers. New York: St. Martin.

Severi, Carlo. 1982. Le chemin des metamorphoses: un modèle de connaissance de la folie dans un chant chamanique kuna. Res: Anthropology and Aesthetics 3:32-67.
2015 (2007). The Chimera principle: an anthropology of memory and imagination. Chicago: Hau.

Silverstein, Michael. 1976. Shifters, linguistic categories, cultural description. In Meaning in anthropology. K. Basso and H. Selby, eds. Pp. 11-55. Albuquerque: University of New Mexico Press.

Strathern, Marilyn. 1991. Partial connections. Savage, MD: Rowman \& Littlefield.

Taylor, Anne-Christine. 1993. Des fantomes stupefiants: langage et croyance dans la pensee Achuar. l'Homme 126-128(XXXIII, 2-4):429-447.

Varzi, Roxanne. 2006. Warring souls: youth, media, and martyrdom in postrevolution Iran. Durham, NC: Duke University Press.

Vidal-Naquet, Pierre. 1996. Foreword. In The masters of truth in archaic Greece. M. Detienne. Pp. 7-14. New York: Zone.

Viveiros de Castro, Eduardo. 1986. Arawete, os deuses canibais. Rio de Janeiro, Brazil: Jorge Zahar/Anpocs.

. 1992. From the enemy's point of view: humanity and divinity in an Amazonian society. Chicago: University of Chicago Press.

- 1996. Os pronomes cosmologicos e o perspectivismo Amerindio. Mana 2(2):115-144.

- 1998a. Cosmological perspectivism in Amazonia and elsewhere. General Lectures, Department of Social Anthropology, University of Cambridge, February 17-March 10.

1998b. Cosmological deixis and Amerindian perspectivism. Journal of the Roval Anthropological Institute 4(3):469-488.

2004. Exchanging perspectives: the transformation of objects into subjects in Amerindian sociologies. Common Knowledge 10(3):463-484.

- 2007. The crystal forest: notes on the ontology of Amazonian spirits. Inner Asia 9:13-33.

. 2009. Intensive filiation and demonic alliance. In Deleuzian intersections in science, technology, and anthropology. C. B. Jensen and K. Rodje, eds. Pp. 305-355. Oxford: Berghahn.

Wagner, Roy. 1977. Scientific and indigenous Papuan conceptualizations of the innate: a semiotic critique of the ecological perspective. In Subsistence and survival: rural ecology in the Pacific. T. Bayliss-Smith and R. G. Feachem, eds. Pp. 385-410. London: Academic Press.

Whitehead, Alfred North. 1978 (1929). Process and reality: an essay in cosmology. Corrected ed. D. R. Griffin and D. W. Sherburne, eds. New York: Free Press. [MN]

Williams, Bernard. 2001. Nietzsche: the gay science. Cambridge: Cambridge University Press.

This content downloaded from 081.096.156.128 on November 07, 2017 02:07:14 AM 